\title{
Properties of Thin Film-Covered GaN(0001) Surfaces
}

\author{
Miłosz Grodzicki 1,2,* \\ 1 Institute of Experimental Physics, University of Wrocław, pl. M. Borna 9, Poland; \\ Milosz.Grodzicki@uwr.edu.pl \\ 2 Łukasiewicz Research Network - PORT Polish Center for Technology Development, Wrocław, Poland
}

Received: 2 April 2020; Accepted: 12 May 2020; Published: 13 May 2020

\begin{abstract}
In this paper surface properties of bare and film-covered gallium nitride $(\mathrm{GaN})$ of the wurtzite form, (0001) oriented are summarized. Thin films of several elements: manganese, nickel, arsenic and antimony are formed by physical vapour deposition method. The results of the bare surfaces as well as the thin film/GaN(0001) phase boundaries presented are characterized by X-ray and ultraviolet photoelectron spectroscopies (XPS, UPS). Basic information about electronic properties of $\mathrm{GaN}(0001)$ surfaces are shown. Different behaviours of thin films after post-deposition annealing in ultrahigh vacuum conditions such as surface alloying, subsurface dissolving and desorbing are found. The metal films form surface alloys with gallium (NiGa, MnGa) while the semi-metals (As, $\mathrm{Sb}$ ) layers easyily evaporate from the $\mathrm{GaN}(0001)$ surface. However, the layer in direct contact with the substrate can react with it modifying the surface properties of $\mathrm{GaN}(0001)$.
\end{abstract}

Keywords: $\mathrm{GaN}(0001)$; thin films; manganese (Mn); nickel (Ni); arsenic (As); antimony (Sb); alloying; photoelectron spectroscopy

\section{Introduction}

The intensive development of research related to gallium nitride (GaN) falls out in the second half of the 1990s. This was due to the improvement of GaN crystals quality, and their availability on the market, as well as controlling doping techniques, which opened the door for wide use in modern electronic devices [1-3]. The upward trend of research continues to this day, proving the attractiveness of this semiconductor. This stems from the fact that GaN, especially in the wurtzite structure, has much more high application potential in the light-emitter, high-power and highfrequency fields compared to the conventional III-V semiconductors, i.e., GaAs, GaSb [4-10]. This is due to its unique physicochemical properties as a wide and direct band gap along with high- electron mobility, -thermal conductivity, and -breakdown voltage. Further, GaN, due to its high chemical and thermal resistance, enables electronic equipment operates under harsh conditions, in contrast to electronic devices based on the well-established silicon or germanium semiconductors. The high popularity of GaN-based materials is also due to the easy way of bands structure tuning by substituting one of elements for another from the same atomic group, creating a new III-N alloy of the wurtzite form $[8,10]$. An operation of the GaN-based device depends on the quality of heterostructures, which in turn is subject to the starting GaN surface. The (0001) surface terminated with gallium atoms is the most commonly used form of $\mathrm{GaN}$ in electronics industry, therefore it is important to get a deep insight into properties of the GaN(0001) surfaces. In turn, the properties of thin-film systems, especially the metallic films deposited on semiconductors, are also extremely important because they are basic and necessary parts of all electronic structures. The simple device, i.e., contact, plays a crucial role in the functionality of electronic components and may show a different electrical behaviour. It can have the Ohmic or Schottky characteristic. However, both these types are extremely substantial for electronics. The contact behaviour for the GaN-based electronic 
device is determined by the properties of the thin film/GaN phase boundary, which depends on the properties of the bare $\mathrm{GaN}(0001)$ surface itself and the characteristics of the deposited material. Manganese (Mn), nickel (Ni), are present in many electronic devices [9]. It was found that $\mathrm{Mn}$ is a very attractive material for creating a ferromagnetic $\mathrm{MnGaN}$ semiconductor by i.a. molecular beam epitaxy (MBE) [11,12] and therefore for creating hybrid systems with spintronic potential [13,14]. Mn on GaN were studied using scanning tunnelling microscopy (STM) technique [15-19] as well as by photoemission experiments [20-24]. Thin films of $\mathrm{Ni}$ on GaN were studied in the works [25-31]. This chemical element is a candidate for contacts with $\mathrm{GaN}$. The electric contacts using $\mathrm{Pd} / \mathrm{Ni}$ bilayers improve device performance [32]. The interfacial reaction between nickel and $\mathrm{GaN}$ can occur during annealing [33], which is a commonly used step for contact creation. This can lead to a formation of new alloys Ni-Ga, similar as in the case of the Pd/GaN interface [34], that have catalytic potential [3541]. In addition to metals, another interesting group of materials deposited as thin layers on GaN surfaces are semi-metals, such as arsenic (As) and antimony (Sb). Processes of MBE growth with As [42-45] and antimony $\mathrm{Sb}[46,47]$ as surfactants were performed to increase the quality of GaN films. Further, As incorporated into GaN changes electronic properties of the host [48-51]. Antimony was also used to modify properties of GaN [52-54] and to form GaNSb films with p-type character [55,56]. The interaction of As and $\mathrm{Sb}$ with $\mathrm{GaN}$ as well as morphological changes caused by post-deposition annealing were studied in Refs. [57,58], where it is shown that thermal treatment leads to easy desorption of the films but some adsorbated atoms remain on the surface modifying its properties.

The basic studies of the interface between GaN and thin layers attracts a lot of attention in both the fundamental and application research. However, in order to interpret them correctly, it is necessary to understand the differences of electronic structure of bare n-, p- and non-doped GaN (0001) surfaces. Despite the very rich availability of professional literature in these topics, and very good extensive review works [59-61], there are still papers with misinterpretation of the basic results obtained in photoemission experiments. This is among others due to: (i) relatively difficult cleaning procedure of GaN surface, which may lead to changes in its stoichiometry. The bare and metalcovered surface can easily be enriched with gallium [29,34,62], which can lead to a bad interpretation of the deconvoluted Ga-3d components; (ii) the presence of a large number of Ga Auger lines which may overlap others core level spectra; and (iii) surface photovoltage (SPV) effects which can cause changes in the Fermi level position versus the valence band maximum $[63,64]$. Further, SVP can sometimes even lead to appearance of a quasar Fermi level in the metal/GaN system [30], which can be mistakenly interpreted as a chemical shift.

Herein the differences between photoelectron spectra of bare $\mathrm{GaN}(0001)$ achieved by three various X-ray sources, i.e., non-monochromatic $\mathrm{Mg} K_{\alpha}(1253.6 \mathrm{eV})$, non- and monochromatic $\mathrm{Al} K_{\alpha}$ $(1486.7 \mathrm{eV})$ are presented. Such information shows differences in spectra and is particularly useful for materials research, where the correct interpretation of the results can be problematic. This article also presents a review of the author's studies on thin films on the GaN(0001) surface including the metals (Mn, Ni) and the semi-metals (As, Sb). Further, this paper shows three scenarios of thin film behaviour under an influence of annealing in ultrahigh vacuum (UHV) conditions: (i) surface alloying for the Ni, Mn metals; (ii) dissolving in subsurface layers of the substrate in reference to Mn; (iii) and desorbing in the case of the As, $\mathrm{Sb}$ semi-metals. The results show that the electronic properties of the $\mathrm{GaN}(0001)$ surface obtained after evaporation of thin-films are modified by dissolution or by presence of reacted adsorbate layer.

\section{Method}

All results presented in this paper were obtained on samples of non-doped, n- and p-type wurtzite $\mathrm{GaN}(0001)$ epilayers which had been grown using metal-organic vapour phase epitaxy (MOVPE). Most thin films were deposited in a standard UHV chamber using physical vapour deposition (PVD) method with one exception of arsenic which were also deposited by PVD but in an MBE chamber interconnected with an analytic system. The formation of thin films systems as well as measurement were done in situ at room temperature (RT). The physicochemical properties of the bare and thin film-covered $\mathrm{GaN}(0001)$ surfaces are obtained by means of X-ray photoelectron 
spectroscopy (XPS) using non-monochromatic $1253.6 \mathrm{eV}$ or non- and monochromatic $1486.7 \mathrm{eV}$ photons. The electronic properties were measured using ultraviolet photoelectron spectroscopy (UPS) with a non-monochromatic excitation source of $21.2 \mathrm{eV}$. Photoelectrons were collected by a hemispherical electron energy working in a constant analyzer energy mode (CAE) with a step size of $0.05 \mathrm{eV}$ or $0.1 \mathrm{eV}$ and a pass energy of $20 \mathrm{eV}$ in case of XPS measurements. A step size of $0.025 \mathrm{eV}$ and a pass energy of $2 \mathrm{eV}$ were applied for UPS experiments. All binding energies (BEs) were referred to the Fermi level $\left(E_{\mathrm{F}}\right)$ the position of which was determined using an Ar-ion cleaned reference $\mathrm{Ag}$ sample. No charge effect of samples was observed, thus no BE corrections were performed for presented data. Structural analysis presented herein was carried out by low-energy electron diffraction (LEED) technique.

\section{Results and Discussion}

\subsection{Bare GaN(0001) Surface}

The GaN material contains gallium and nitrogen atoms in 1:1 stoichiometry forming the hexagonal N-Ga diatomic layer in which the atoms are arranged in an imperfect tetrahedral geometry due to different atom sizes and electronegativity of $\mathrm{Ga}$ and $\mathrm{N}$ atoms. The hexagonal N-Ga diatomic layers forming hcp structure can be stacked on top of each other in c-direction taking places A, B or $C$, as shown in Figure 1. There are two stable GaN structures with the ABAB ... or ABCABC ... stacking sequences for which GaN crystals are obtained in the form of the wurtzite or the zinc-blend, respectively. In addition to being different in structure, both materials have other electronic properties [65-68]. The $\mathrm{GaN}(0001)$ has the wurtzite form and is terminated with $\mathrm{Ga}$ atoms unlike to the $(000 \overline{1})$ surface on top of which $\mathrm{N}$ atoms are situated.

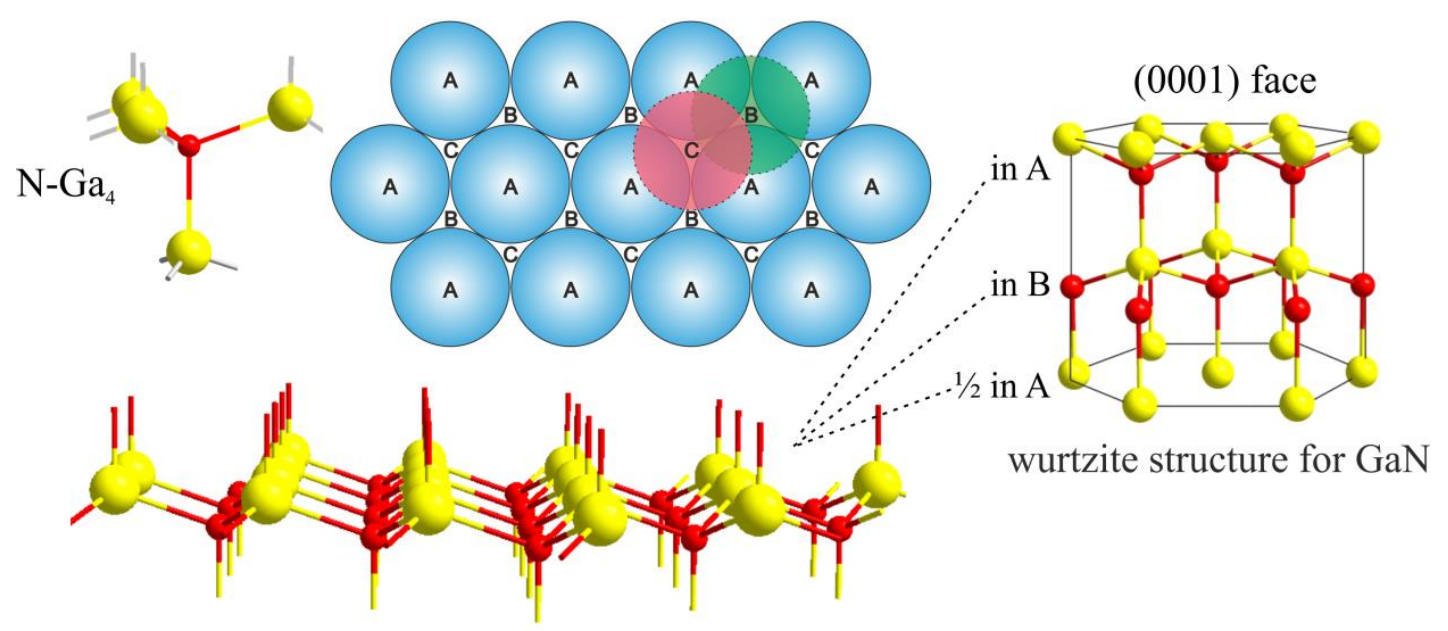

$\mathrm{N}-\mathrm{Ga}$ diatomic layer

Figure 1. Structure of GaN: particle of $\mathrm{Ga}_{4} \mathrm{~N}$ in tetrahedral geometry, N-Ga diatomic hexagonal sheet, hexagonal close-packing (hcp) position model, and hcp structure with layering ABAB type.

Below are the results of the non-doped GaN, (0001)-oriented sample, pre-cleaned with isopropanol then cleaned in situ by one short-time annealing under UHV conditions at a temperature of about $800{ }^{\circ} \mathrm{C}$. The broad XPS spectra of the sample obtained with $1253.6 \mathrm{eV}$ and $1486.7 \mathrm{eV}$ photons are shown in Figure 1. Besides the Ga-2p, Ga-3s, Ga-3p, N-1s peaks from GaN, the C-1s, O-1s corelevel lines that are derived from carbon and oxygen impurities are also visible. Auger electrons emitted from a sample exposed to X-rays also contribute to the collected spectra. They form characteristic energy levels from Auger transitions in atoms presented on surfaces and subsurface layers. In Figure 2 there are many electrons from Ga LLM transitions, and especially two intensive levels, i.e., the $\mathrm{L}_{3} \mathrm{M}_{45} \mathrm{M}_{45}$ and $\mathrm{L}_{2} \mathrm{M}_{45} \mathrm{M}_{45}$ with kinetic energies of about $1065 \mathrm{eV}$ and $1091 \mathrm{eV}$, respectively. It is also worth noting that the kinetic energy of Auger electrons does not depend on the energy of 
excitation radiation (unlike photoelectrons). Thus the same Auger level in spectra obtained with different photon energies are located at different places of BE, as shown in Figure 2. Further, in the case of measurements with $\mathrm{Mg} K_{\alpha}$ excitation line, a carbon content on GaN surfaces cannot be determined because the $\mathrm{C}-1 \mathrm{~s}$ line is covered by one of the Ga LMM levels. For experiments with $\mathrm{Al}$ $K_{\alpha}$ photons, the N-1s line partly overlaps with the Auger signal.

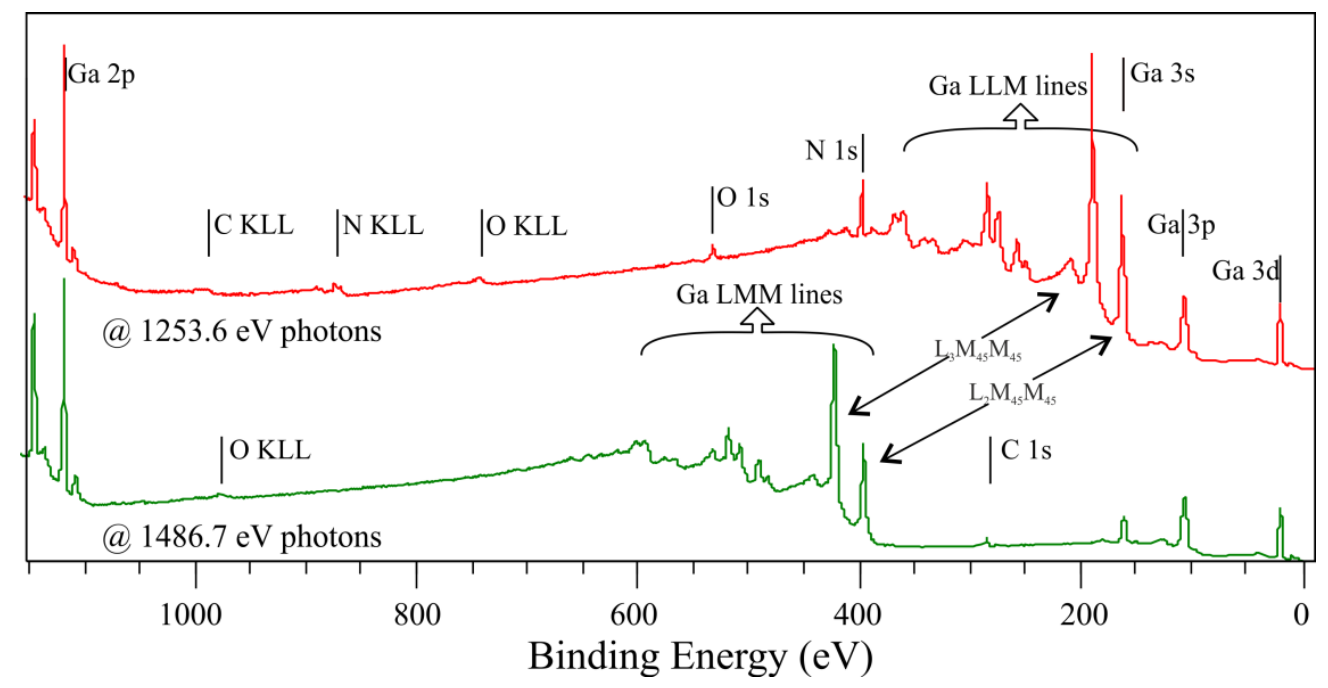

Figure 2. Survey spectra for non-doped $\mathrm{GaN}(0001)$ surface collected with different photon energies.

The influence of standard commonly used radiation sources on the obtained spectra shape is shown in Figure 3. On the GaN(0001) surface, where a trace amount of oxygen is presented, the Ga$3 \mathrm{~d}$ shallow core-level line with a BE of $20.4 \mathrm{~V}$ contains four sub-peaks. The main one being from the Ga-N bonds, the two other, corresponding to $\mathrm{Ga}-\mathrm{O}$ and $\mathrm{Ga}-\mathrm{Ga}$ bonds, and the last one coming from the overlap $\mathrm{N}-2 \mathrm{~s}$ state $[22,51,69]$. The $\mathrm{X}$-ray source type has a little effect on the shape of Ga-3d peaks obtained, but this is not the case for the valence band (VB), where the impact is significant, as shown in Figure 3 a. This is due to the overlap of the X-ray satellite of the Ga-3d on the VB measured with non-monochromatic sources and the different depths from which the electrons originate. The kinetic energy of ejected electrons from the VB excited with $1253.6 \mathrm{eV}\left(\mathrm{Mg} K_{\alpha}\right)$ and $1486.7 \mathrm{eV}\left(\mathrm{Al} K_{\alpha}\right)$ photons varies significantly causing them to have different inelastic mean free paths. This results in that signals collected with different photon sources come from various sample depths.

Despite different shapes, the valence band maximum (VBM) is located $2.7 \mathrm{eV}$ below the $E_{\mathrm{F}}$, found from a linear extrapolation of the leading edge of the spectrum to the background. In Figure $3 \mathrm{~b}$ the $\mathrm{N}-1$ s spectrum collected with $\mathrm{Mg} K_{\alpha}$ photons consists of two elements: the first is assigned to the NGa bonding with the $\mathrm{BE}$ of $397.8 \mathrm{eV}$, and the second to $\mathrm{N}-\mathrm{H}$ bonds. This spectrum obtained with $\mathrm{Al}$ $K_{\alpha}$ excitation line has five sub-peaks: similarly, the first two peaks corresponding to the N-Ga and N$\mathrm{H}$ bonds and the others coming from the Ga LMM. The Auger signal is suppressed for measurements with a monochromator. The energy difference between the $\mathrm{N}-1 \mathrm{~s}$ and Ga-3d peaks is $\Delta \mathrm{E}_{\mathrm{N}-\mathrm{Ga}}^{\mathrm{GaN}}=$ $\mathrm{BE}(\mathrm{N} 1 \mathrm{~s})-\mathrm{BE}(\mathrm{Ga3d})=377.4 \mathrm{eV}$ and is consistent with other literature for GaN [63]. 

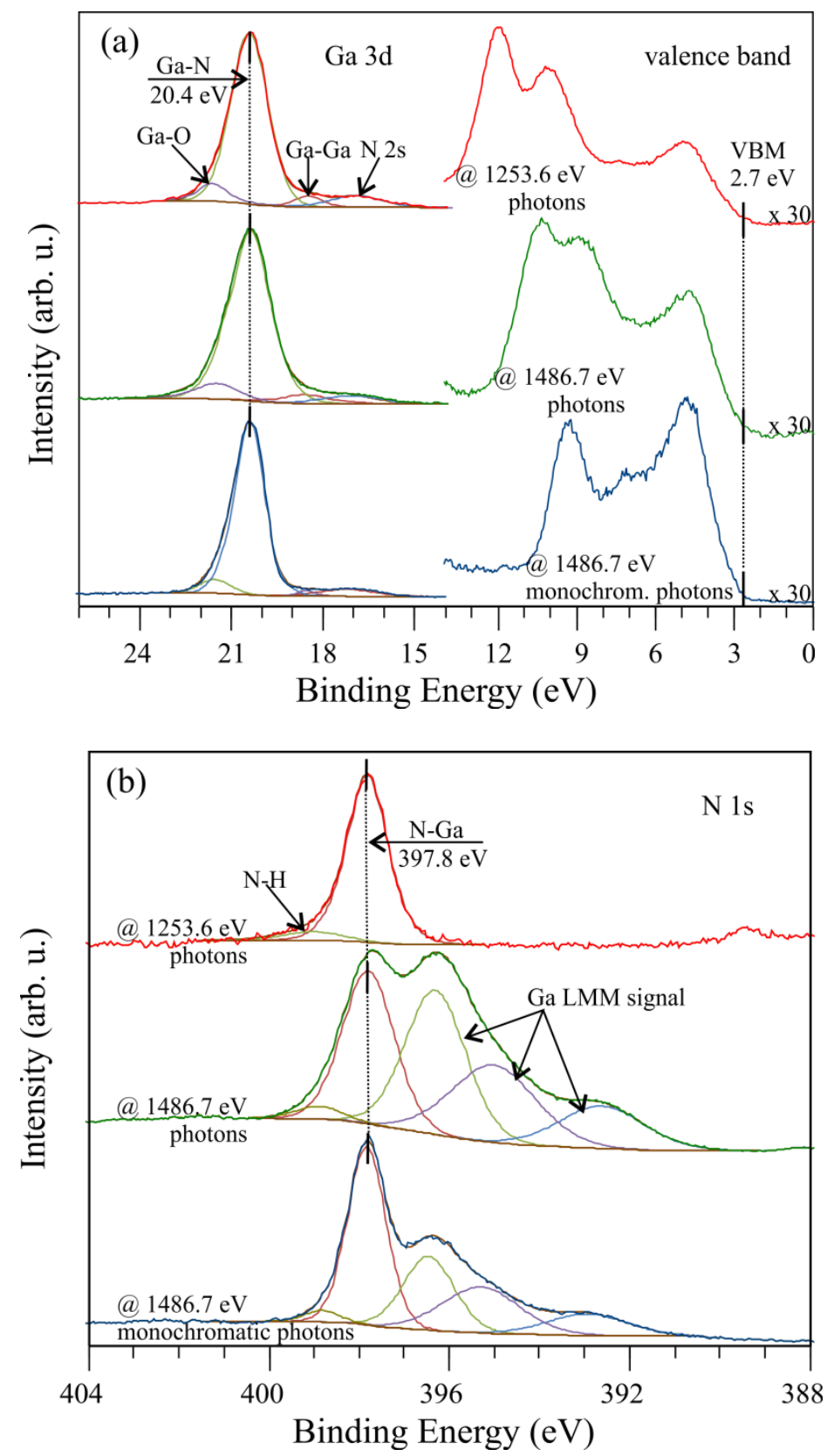

Figure 3. XPS spectrum of (a) the Ga $3 \mathrm{~d}$ and valence band as well as (b) the $\mathrm{N} 1 \mathrm{~s}$ for non-doped $\mathrm{GaN}(0001)$ surface collected with different photon sources.

Cleaning the surface of GaN crystals under UHV is problematic because it can lead to changes in the surface stoichiometry regardless of whether it is an ion bombardment or annealing. Ion bombardments may introduce defects and preferentially remove nitrogen atoms [62,70,71]. To eliminate this effect post-bombardment annealing method or a low energy $\mathrm{N}$-ion bombardment can be utilized [72-74]. The most convenient and simplest technique of surface preparation in UHV is annealing. However during this process the surface may also be decomposed [75]. Thus rapid thermal annealing (RTA) should be applied. The effect of carbon and oxygen contaminants elimination by this method is shown in Figure 4. One can see that annealing in UHV may lead to achieving the carbon- and oxygen-free $\mathrm{GaN}(0001)$ surface. Unfortunately, sometimes this method does not cause complete elimination of contaminants, of which XPS signals remain on the level as middle curves in Figure 4. This is most likely dependent on the results of pre-cleaning sample surface by chemical treatment prior placing it in UHV systems. 


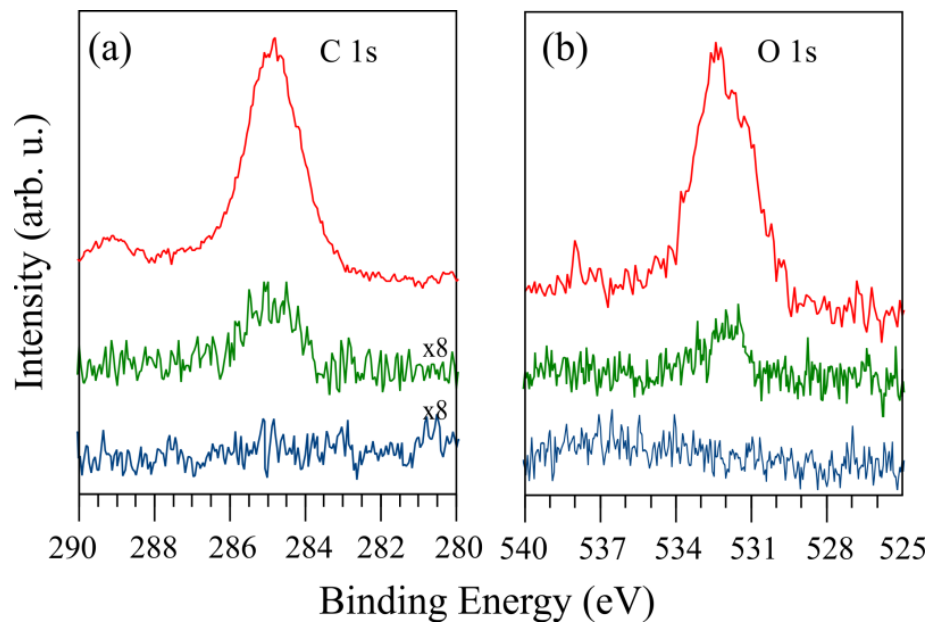

Figure 4. XPS spectrum intensity of (a) the $C 1$ s and (b) the $\mathrm{O} 1$ s for non-doped GaN(0001) surface. Upper spectrum corresponds to the degassed surfaces in UHV, lower ones show influence of different number of annealing cycles at $800^{\circ} \mathrm{C}$.
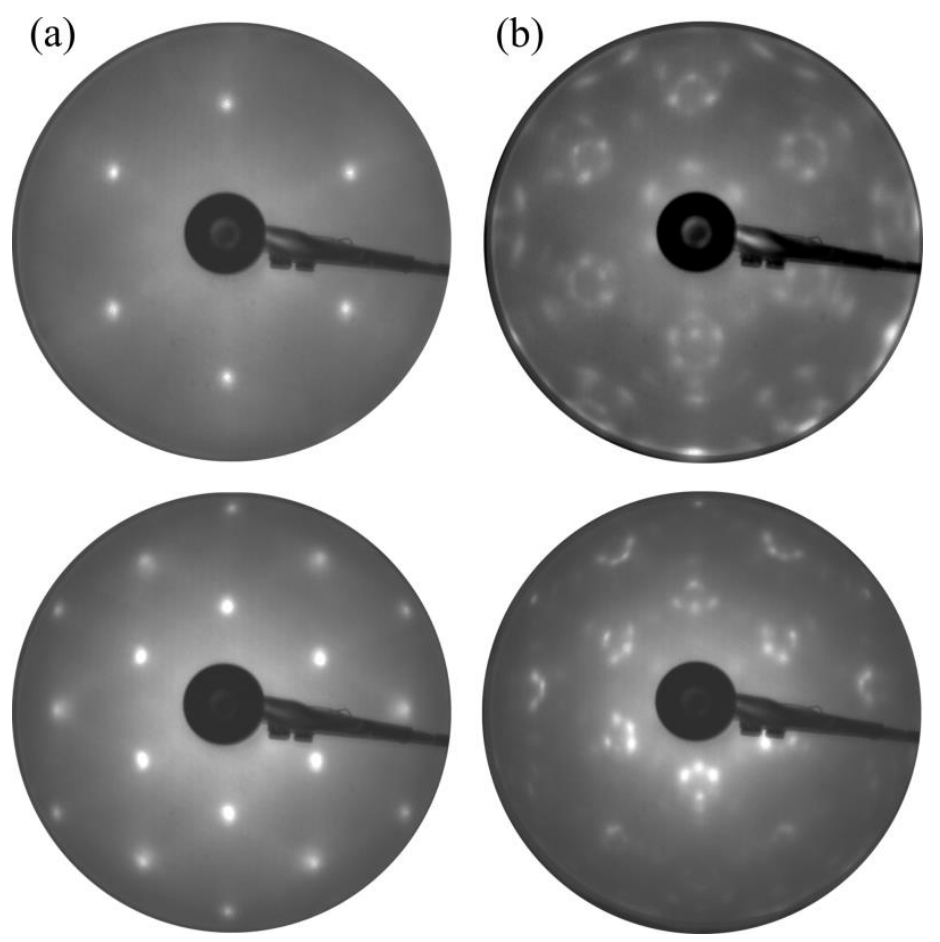

Figure 5. LEED patterns for GaN(0001)-(1x1) structure. Image (a) is attributed to flat well-ordered surfaces, (b) shows presence of facets. Images are taken with electron beam of $90 \mathrm{eV}$ (upper) and 155 $\mathrm{eV}$ (bottom).

RTA can also guarantee obtaining a high-quality surface as confirmed by LEED patterns in Figure $5 \mathrm{a}$, where the strong intensity and sharp spots of $\mathrm{GaN}(0001)-(1 \times 1)$ are visible. Several cycles of RTA may rebuild the surface forming a facet-like terrace structure changing the diffraction pattern [76,77]. As a result of such rebuilding the sextets of diffraction spots appeared in hexagonal configuration around each main spot, see Figure $5 \mathrm{~b}$. The energy positions of core level line measured by XPS may vary significantly depending on the type and concentration of the dopant used in GaN. Those peak shifts do not necessarily result from the chemical properties of the surface, but may only arise from different locations of the Fermi level in n-, p- and non-doped GaN. In the perfect, nondoped GaN, the $E_{\mathrm{F}}$ in bulk falls more or less in the middle of the forbidden gap, in the n-type it is located close to the conduction band minimum and in the p-type it is placed near the valance band 
maximum. Since photoemissions are surface-sensitive techniques, the $E_{\mathrm{F}}$ position on the surface of the tested material is crucial. Due to surface density of states present on the $\mathrm{GaN}(0001)$ the surface Fermi level is located in a different location than in bulk [78-80,64]. This causes that the energy bands at the surface are bent upwards or downwards depending on the dopant type. Figure 6 shows the distance between the valence band maximum and the surface Fermi level for Si- (n-), Mg- (p-) and non-doped GaN.

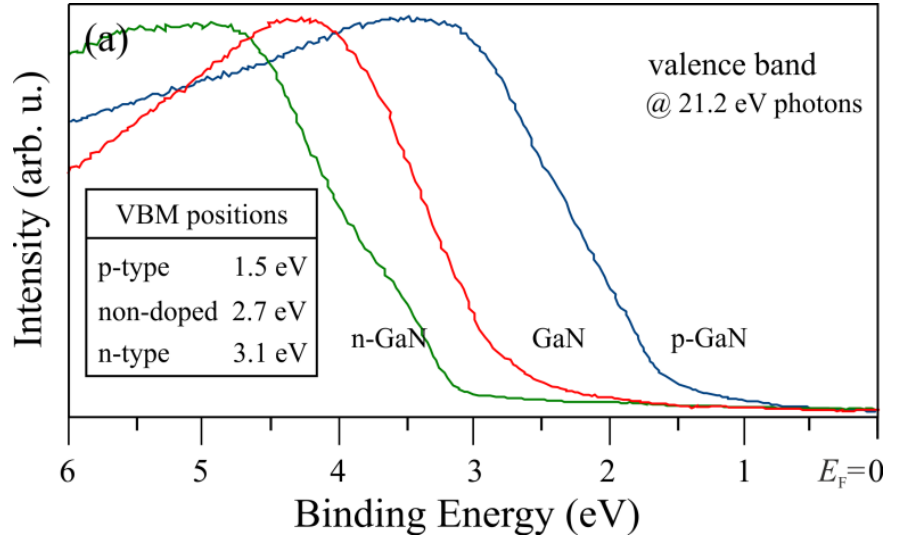

(b)

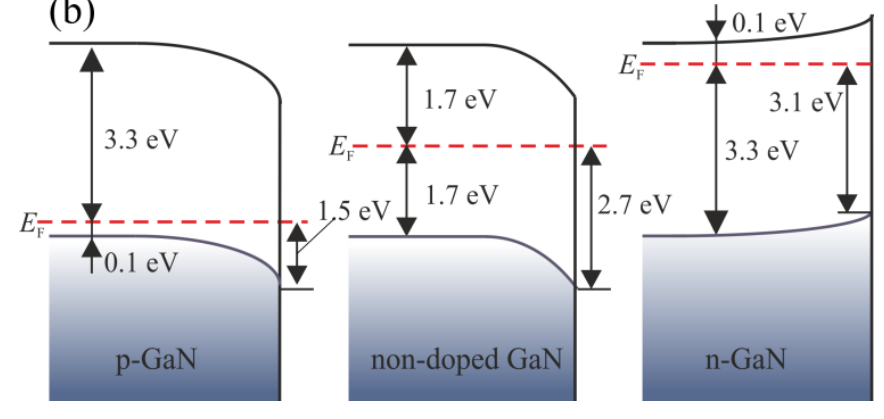

Figure 6. (a) UPS spectra of valence band for n-, p- and non-doped GaN(0001). (b) Energy band diagrams visualisation of (a). The Fermi level positions in bulk materials were determined for $n-$ and p-type GaN with the carrier concentration of $5 \times 10^{16} \mathrm{~cm}^{-3}$ and $5 \times 10^{17} \mathrm{~cm}^{-3}$, respectively.

Further, it indicates the difference in the EF location on the surface and bulk. Moreover, SPV appears on GaN during XPS and UPS measurements, as a result of which the band bending changes $[63,64]$. Thus, the surface $E$ F position relative to the VBM may also vary depending on the magnitude of the SPV. Therefore, to determine whether the peak shift is caused by chemical reaction or not, its location relatively to the VMB needs to be known. For instance on the well-prepared $\mathrm{GaN}(0001)$ surface the Ga-3d state is located around $17.7 \mathrm{eV}$ ) above the VBM. For the non-doped GaN $\Delta E v=\mathrm{Ga}-$ $3 \mathrm{~d}-\mathrm{VBM}=17.7 \mathrm{eV}$, from the results shown in Figure 3a. There are also different values of the $\Delta E$ in literature with a spread of $\pm 0.3 \mathrm{eV}$ from that indicated here.

\subsection{Mn on $\mathrm{GaN}(0001)$}

Manganese belongs to the transition metals, group VII in the periodic table. The element exhibits poor electrical and thermal conductivity properties. Manganese has a density of $7.2 \mathrm{~g} / \mathrm{cm}^{3}$, its thermal conductivity is $7 \mathrm{~W} /\left(\mathrm{m} \cdot{ }^{\circ} \mathrm{C}\right.$ ) and its electrical resistivity amounts to $1.6 \times 10^{-6} \Omega \cdot \mathrm{m}$ (at RT). It melts at $1246{ }^{\circ} \mathrm{C}$ and its boiling point is $2061{ }^{\circ} \mathrm{C}$ (under standard pressure). Mn needs a high temperature to be evaporated in a vacuum and at $930{ }^{\circ} \mathrm{C}$ has a vapour pressure of $10^{-8} \mathrm{mbar}$. Manganese has multifaceted field of industrial uses from metallurgy, particularly in stainless steels, to electronic applications.

Surface techniques were used to measure the interfacial behaviour of $\mathrm{Mn}$ and $\mathrm{GaN}$ in the context of the possible formation of diluted magnetic semiconductor layers. The studies were inspired by spintronic potential of MnGaN alloys [12-14]. Thin films of $\mathrm{Mn}$ on GaN are mainly reported for the 
$(000 \overline{1}), \mathrm{N}$-terminated, surfaces [18-20,81-83]. These works, generally, refer to structural analysis for ultra-thin coverages. One exception of this is Ref. [20], where the interaction of Mn with GaN(0001) is investigated by photoemission experiments with a synchrotron radiation. Results of Mn thin films on the GaN(0001) surfaces concerned structural characterization by STM are reported in Refs. [1517]. Whereas physicochemical properties of $\mathrm{Mn}$ on $\mathrm{GaN}(0001)$ studied by the author using XPS and UPS with non-monochromatic excitation sources are in works [22-24].

Early stages of coating the non-doped GaN(0001) surface with Mn films and the influence of annealing on the system properties are described in Ref. [22,23]. The growth of Mn film by PVD and characterisation were performed in situ on MOCVD GaN(0001). The initial bare surface that was prepared by RTA exhibited the $(1 \times 1)$ structure (confirmed by LEED similar to that in Figure 5 a) and had a trace amount of oxygen. In these works, the Mn films formed at RT gave no diffraction patterns indicating that they are amorphous. The changes of the Ga-3d, N-1s and Mn-2p core level lines with thickness of deposited Mn film are shown in Figure 7. The peaks of the bare surface contained the same components as already presented in Figure 3. Namely, the sub-peaks for the Ga-3d are from the Ga-N, Ga-O, Ga-Ga bonding and the N-2s state. The sub-peaks for the N-1s origin from the N-Ga, N$\mathrm{H}$ bonds. One can see that the substrate XPS lines shift towards a lower BE after deposition of Mn films. The Mn-3p peak behaves in the same manner.
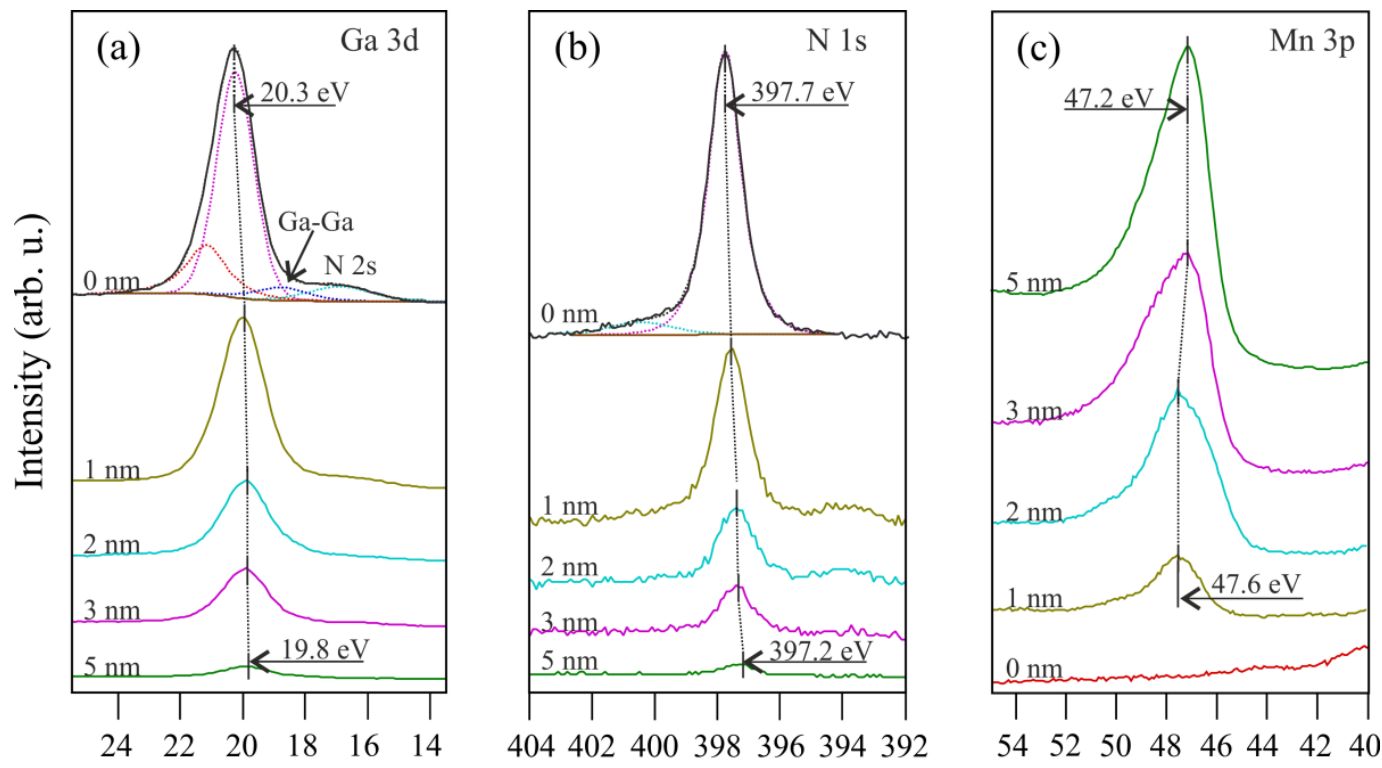

Binding Energy (eV)

Figure 7. Evolution of spectra for (a) Ga-3d, (b) N-1s and (c) Mn-3p with the thickness of deposited Mn film. XPS measurements were performed with non-monochromatic $1253.6 \mathrm{eV}$ photons. (Data previously published in [22]).

The peak shifts are a result of charge transfer through the $\mathrm{Mn} / \mathrm{GaN}$ phase boundary and not a chemical reaction of Mn with the GaN. Mn films behave unlike those deposited on the (000-1) surface [20]. The electron transfer at the interface causes the formation of the Schottky barrier the height of which $(\mathrm{SBH})$ can be simply calculated from the formula: $\mathrm{SBH}_{\mathrm{GaN}}^{\mathrm{Mn}}=\mathrm{E}_{\mathrm{g}}-\mathrm{VBM}_{\mathrm{GaN}}^{\mathrm{Mn}}$, where $\mathrm{E}_{\mathrm{g}}=3.4 \mathrm{eV}$ is the band gap of the $\mathrm{GaN}$, and $\mathrm{VBM}_{\mathrm{GaN}}^{\mathrm{Mn}}$ is the position of $\mathrm{VBM}$ at the interface after Mn deposition. The latter value cannot be obtained directly from UPS measurements since the GaN is coated with the Mn which introduces new electron density of states (DOS). This causes that the VB of the GaN is no longer visible, as presented in Figure 8. However, the VBM for the thin film-covered GaN can be determined indirectly from the Ga-3d peak shift due to the energy distance between the Ga-3d and the $\mathrm{VBM}$ is constant $\mathrm{Ga} \mathrm{d}_{\mathrm{GaN}}-\mathrm{VBM}_{\mathrm{GaN}}=\mathrm{Ga}_{\mathrm{G}} \mathrm{M}_{\mathrm{GaN}}^{\mathrm{Mn}}-\mathrm{VBM}_{\mathrm{GaN}}^{\mathrm{Mn}}$. This procedure was previously applied to metal films on $\mathrm{SiC}[84,85]$. In Figure 9 the energy level diagrams of the bare $\mathrm{GaN}(0001)$ and $\mathrm{Mn} / \mathrm{GaN}(0001)$ interface with the SBH is constructed based on the UPS and XPS data. 


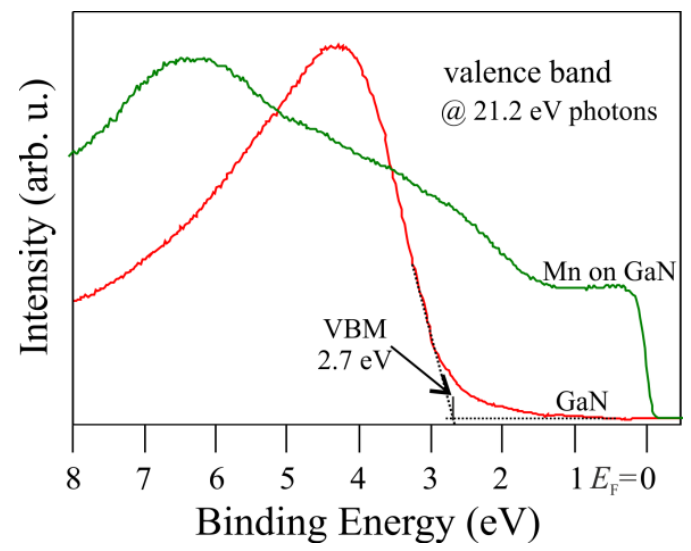

Figure 8. UPS spectra of valence band for bare and Mn thin-covered GaN(0001) surface.

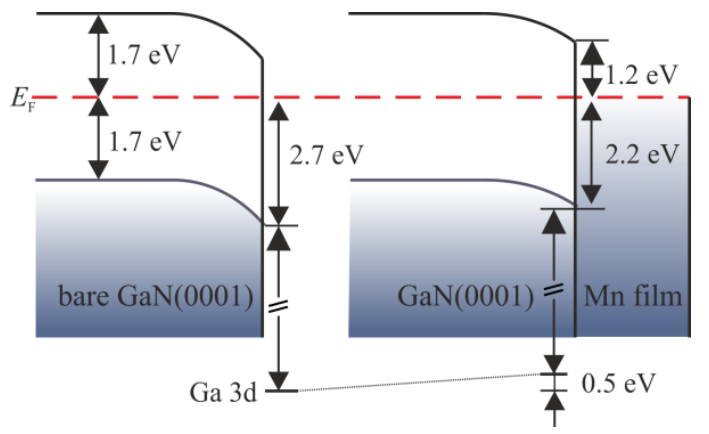

Figure 9. Energy band diagrams for bare and Mn film-covered GaN(0001) surface. As seen SBH can be simply calculated based on photoelectron spectroscopy measurements.

Annealing of the Mn films on GaN(0001) in UHV is interesting from the aspect of the Mn-diluted GaN semiconductor formation. The dissolution of Mn atoms in bulk GaN(000-1) induced by thermal treatment was observed using STM [18] and secondary ion mass spectrometry (SIMS) [86]. (Mn)GaN films obtained that way show a ferromagnetic behaviour [87]. Experiments facing the changes of physicochemical properties of the films on the $\mathrm{GaN}(0001)$ crystals under an influence of annealing are presented in the author's works [23,24]. In Ref. [23] the Mn film-covered non-doped GaN(0001) was annealed at $500{ }^{\circ} \mathrm{C}$ followed by $800{ }^{\circ} \mathrm{C}$ for $3 \mathrm{~min}$ for each temperature. The process strongly modified the morphology of the system. The Mn films on $\mathrm{GaN}(0001)$, which are amorphous as grown, crystallize following annealing at $500{ }^{\circ} \mathrm{C}$. LEED patterns for this stage reveal diffraction rings, as shown in Figure 10 a. They come from randomly oriented rotational domains of $(2.3 \times 2.3)$ structure in relation to the substrate, giving the lattice parameter equal 7.3 $\AA$. This value matches the $\alpha$-Mn(111) for which the surface lattice constant is from $7.39 \AA$ to $7.68 \AA$ [88]. The small transformation of the lattice can be attributed to Ga incorporation into the Mn structure. After annealing at $800^{\circ} \mathrm{C}$ the thin film alters into the well-ordered MnGa surface alloy. The LEED pattern, in Figure $10 \mathrm{~b}$, exhibits three sets of $(1.21 \times 1.21)$ squareR15 structures coming from the film with lattice constant equal to $3.86 \AA$. They are rotated by $60^{\circ}$ relatively to each other. The achieved lattice parameter is in line with the structure of the single-phase $\mathrm{Mn}_{1+\mathrm{x}} \mathrm{Ga}(0<\mathrm{x}<1)$ alloys for which the lattice constant is around $3.88 \AA$ [89], clearly demonstrating the formation of alloys on the surface. 

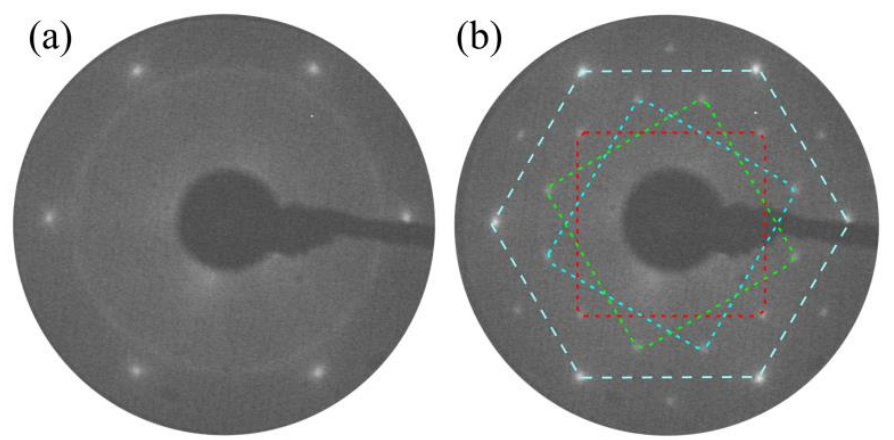

Figure 10. LEED patterns ( $55 \mathrm{eV}$ ) for the $\mathrm{Mn}$ film-covered $\mathrm{GaN}(0001)$ after annealing at (a) $500{ }^{\circ} \mathrm{C}$ and (b) $800^{\circ} \mathrm{C}$. The three domains of the square structure of MnGa alloy and $(1 \times 1)$ hexagonal structure of $\mathrm{GaN}(0001)$ substrate are marked. (Data previously published in [23]).

XPS and UPS provide information on physicochemical properties of the annealed system. The changes of Mn-2p doublet introduced by thermal treatment are presented in Figure 11a. The analysis of the Mn-2 $\mathrm{p}_{3 / 2}$ peak for the non-annealed system shows that it can be fitted by two sub-peaks with BEs of $368.7 \mathrm{eV}$ and $639.75 \mathrm{eV}$. Annealing causes that the $\mathrm{Mn}-23 / 2$ becomes broader and to reproduce its shape another components need to be added with BEs of $641 \mathrm{eV}$ and $642.85 \mathrm{eV}$. Figure $11 \mathrm{~b}$ shows that the Ga-2p $3 / 2$ peak can be fitted by one or two sub-peaks for the non- and annealed system, respectively. They are located at $1117.6 \mathrm{eV}$ and $1116.5 \mathrm{eV}$. The sub-peak at a lower BE in the case of the bare $\mathrm{GaN}(0001)$ surface corresponds more or less to the Ga-Ga bonding but on the annealed Mncovered GaN surface should be attributed to the Mn-Ga bond which has a metallic character with a very weak chemical shift [90]. The sub-peak intensities for both the Mn-2 $\mathrm{p}_{3 / 2}$ and Ga-2 $\mathrm{p}_{3 / 2}$ states depend on annealing temperature. The changes of both the core level lines appearing during annealing are the result of atoms exchange at the phase boundary. There are two processes, i.e., some manganese atoms diffuse into the substrate substituting gallium elements at a subsurface region. In turn, these release Ga atoms directly to the Mn film covered surface. These processes result in the formation of: (i) (Mn)GaN-like alloy which is demonstrated by the two extra sub-peaks in Figure 11 a (curve $2 \& 3$ from the top) [21,91], and was already reported in other works [18,86]; and (ii) the MnGa surface alloy, manifested by second component in Figure $11 \mathrm{~b}$ (curve $2 \& 3$ ). This surface alloying - the intermixing of $\mathrm{Ga}$ atoms with thin film on $\mathrm{GaN}(0001)$ surface is also observed in the case of $\mathrm{Ni}$, Pd adsorbates [29,34].
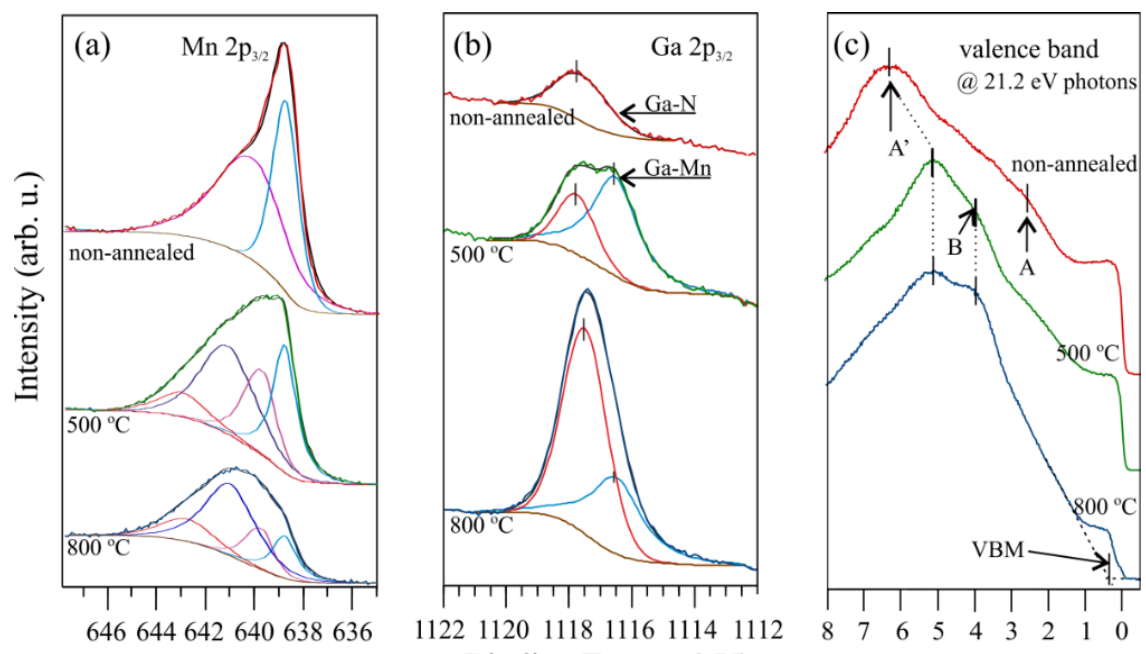

Binding Energy (eV)

Figure 11. Evolution of spectra for (a) Mn-2p, (b) Ga-2d, and (c) valence band for Mn film-covered $\mathrm{GaN}(0001)$ with annealing temperature. (Data previously published in [23]). 
Knowing that $\mathrm{Mn}$ is dissolved in the substrate, it is interesting how the VB modified under an influence of annealing. This information provided UPS measurements, as shown in Figure $11 \mathrm{c}$. A shape for the VB of Mn film-covered $\mathrm{GaN}$ annealed at $500^{\circ} \mathrm{C}$ is changed - the feature marked as $\mathrm{A}$ disappears, the maximum $A^{\prime}$ is shifted towards a low BE and another feature marked with B emerges. Despite the above changes, electron DOS in the vicinity of the $E_{\mathrm{F}}$ is still high, demonstrating a metallic character of the adlayers. Annealing at higher temperature enhances the modification - the feature intensity of $\mathrm{A}^{\prime}$ decreased and of $\mathrm{B}$ increased. The Fermi edge is still visible but its intensity is definitely lower. Moreover it can be seen that the VB of the GaN(0001) Mn doped shifts towards a lower BE and the VBM is $0.4 \mathrm{eV}$ below the $E_{\mathrm{F}}$. This result is very interesting, especially, for $\mathrm{p}-\mathrm{GaN}$ crystals for which the surface Fermi level is far away from the VBM due to band bending at the surface. This leads to a problem with obtaining the Ohmic contacts with this material as was noted in Ref. [92]. The potential to modify the VB of GaN by dissolving Mn thermal initiation has been applied to $\mathrm{p}-\mathrm{GaN}(0001)$ by the author in Ref. [24]. By annealing the Mn film-covered p-GaN under UHV conditions, Mn was dissolved in the subsurface layer of the $\mathrm{p}-\mathrm{GaN}$, similarly as was described above in the case of nondoped GaN. Then, in order to remove the MnGa alloy from the surface, for which UPS showed metallic properties, the system was annealed at $900{ }^{\circ} \mathrm{C}$. After that the obtained surface was free of the adlayer with the metallic character. However, as a result of high temperature, the obtained surface was faceted. The consequence of such process is visible in LEED patterns as extra spots [24] comparable to those presented in Figure $5 \mathrm{~b}$.

XPS and UPS results of the work [24] are presented in Figure 12 which shows changes of the Ga$3 \mathrm{~d}$ and $\mathrm{N}-1 \mathrm{~s}$ core level lines caused by the manganese incorporation. The Ga-3d is located at $19.1 \mathrm{eV}$ and $18.7 \mathrm{eV}$ before and after the Mn incorporation, respectively. Apart the Ga-3d state the Mn-3p peak at $47.5 \mathrm{eV}$ is present on the $\mathrm{p}-\mathrm{GaN}$ Mn co-doped, as shown in Figure 12 a. The N-1s peak shifts towards a lower BE by $0.4 \mathrm{eV}$ to the position of $396.1 \mathrm{eV}$ after the $\mathrm{Mn}$ atoms introduction. So the shifts of the Ga-3d and N-1s are the same, similar observation was also noted in a paper [93], where the Mn implantation by an ion bombardment was applied.
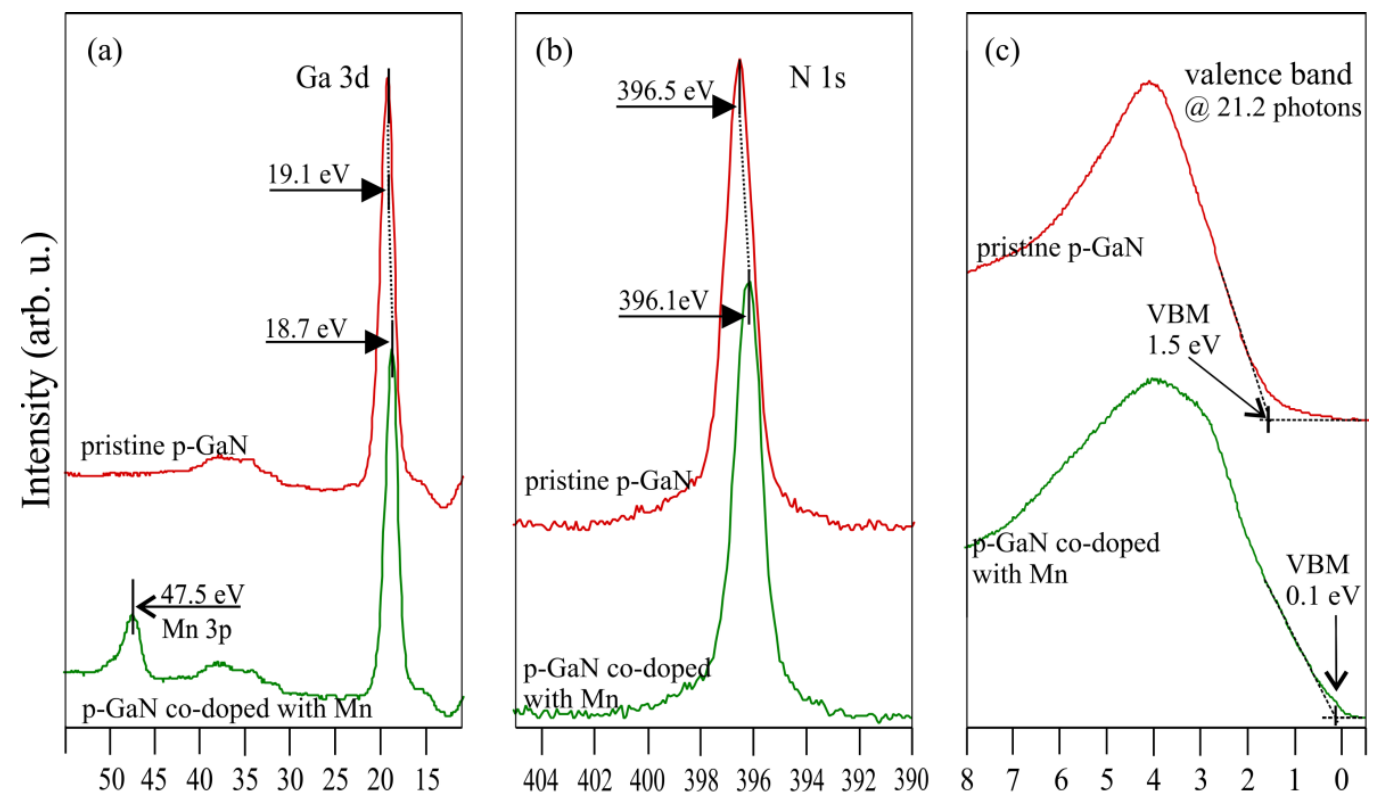

Binding Energy (eV)

Figure 12. XPS spectra of (a) Ga-3d with Mn-3p, (b) N-1s and (c) valence band for pristine p$\mathrm{GaN}(0001)$ substrate and co-doped with $\mathrm{Mn}$ by thermal annealing of $\mathrm{Mn} / \mathrm{GaN}$ system.(Data previously published in [24]).

The presence of $\mathrm{Mn}$ atoms in $\mathrm{p}-\mathrm{GaN}$ has a strong impact on the VB and the effects are especially visible nearby the Fermi level. The VBM is $1.5 \mathrm{eV}$ and $0.1 \mathrm{eV}$ below the $E_{\mathrm{F}}$ for the bare $\mathrm{p}-\mathrm{GaN}(0001)$ surface and the p-GaN Mn co-doped, as shown in Figure 12 c. The VB of the Mn incorporated p-type 
GaN varies significantly the electron DOS begins almost at the Fermi level, its shape is very similar to that for non-doped (Mn)GaN-like alloy, not included the edge of the Fermi, presented in Figure 11. The widening of the VB in the vicinity of the Fermi level follows from the subsurface layers modification caused by $\mathrm{Mn}$ atoms incorporated, leading to the formation of p-type (Mn)GaN-like alloy. This is in line with the literature [94-96], where it is shown that the Mn presence in the GaN matrix reconstructs the VB. Another reason that the VBM is practically located by the Fermi level may be surface states deprivation and thus an elimination of band bending on $\mathrm{GaN}(0001)$. The band energy diagrams constructed based on the UPS and XPS data for the bare p-GaN(0001) and p$\mathrm{GaN}(0001)$ co-doped with manganese is shown in Figure 13. There is a clearly noticeable flattening of the band on the surface of the p-GaN Mn co-doped with the assumption that the band gap does not change.

(a)

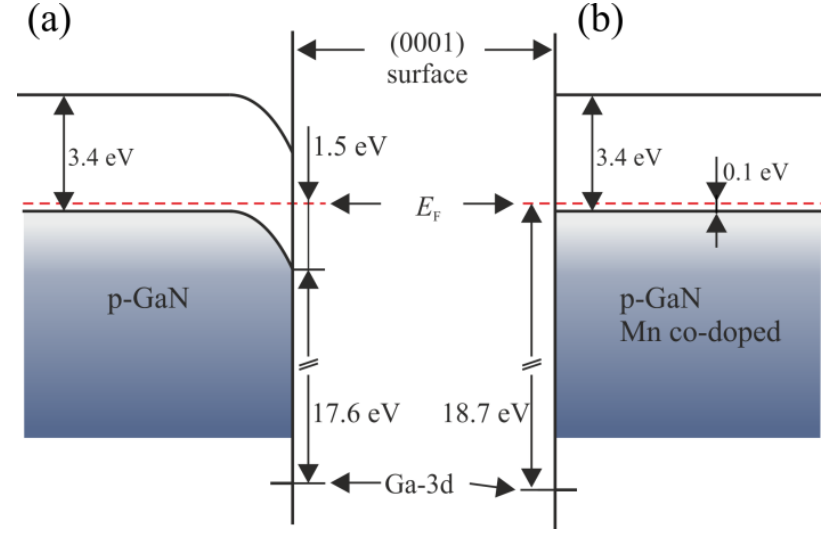

Figure 13. Band structure for (a) pristine p-GaN(0001) surface and (b) p-GaN(0001) co-doped with Mn assuming that band gap does not change.

\subsection{Ni on $\mathrm{GaN}(0001)$}

Nickel is a transition metal, group VIII in the periodic table. The element exhibits good electrical and thermal conductivity properties. Nickel has a density of $8.9 \mathrm{~g} / \mathrm{cm}^{3}$, its thermal conductivity is 91 $\mathrm{W} /\left(\mathrm{m} \cdot{ }^{\circ} \mathrm{C}\right.$ ) and its electrical resistivity amounts to $69 \times 10^{-9} \Omega \cdot \mathrm{m}$ (at RT). It melts at $1455^{\circ} \mathrm{C}$ and its boiling point is $2730{ }^{\circ} \mathrm{C}$ (under standard pressure). Ni needs a high temperature to be evaporated in a vacuum and at $930^{\circ} \mathrm{C}$ has a vapour pressure of $10^{-8} \mathrm{mbar}$. Nickel is used for metal contacts with GaN. It can be applied as a single element layer or multilayer with other elements mainly from nickel family as well as other like gold, silver etc. [26-28,31]. Structural and topographical analysis of Ni on GaN performed by STM was reported in $[97,98]$. The first work concerns the growth mode and the interfacial compounds formation. The second focuses on topographic differences between Ni layers deposited at RT, followed by annealing at $650{ }^{\circ} \mathrm{C}$, and Ni layers deposited on the substrate at $650{ }^{\circ} \mathrm{C}$, as a result of which the surface consists mainly of $\mathrm{Ni}_{3} \mathrm{Ga}$.The latter procedure gives more strongly dispersed films and is better for catalytic converters, where Ni-Ga alloys can be applied [35,36]. Photoemission experiments were carried out to measure the surface conditions effect on properties of obtained contacts to $\mathrm{GaN}$ and the temperature impact on electronic properties of $\mathrm{Ni} / \mathrm{GaN}$ interfaces [99,100]. In Ref [25] physicochemical properties of Ni on GaN were investigated, i.a. with XPS technique. It was shown that a disordered $\mathrm{Ni}$ film grow continuously, in the layer by layer manner (Frank-van der Merwe mode), and the chemical interaction between the adsorbate and the substrate can occur even near RT.

The morphology of $\mathrm{Ni}$ film-covered $\mathrm{GaN}(0001)$ and morphological changes introduced by annealing as well as SPV impact on XPS and UPS results are presented in the author's papers [29,30]. In these studies the growth of Ni film by PVD and the characterisation were performed in situ on the n- and p-type MOCVD GaN(0001) samples. Spectroscopic data are obtained with nonmonochromatic excitation lines. The bare surfaces prepared by RTA under UHV conditions had only small amounts of carbon and oxygen contamination and revealed the $(1 \times 1)$ structure (confirmed by 
LEED similar to that in Figure 5 a) In these works, the Ni films formed at RT exhibited no diffraction pattern, indicating that they are amorphous. After deposition of $\mathrm{Ni}$ film on the bare n-type $\mathrm{GaN}(0001)$ surface the Ga-3d core level line shifts towards a lower BE by $0.5 \mathrm{eV}$ to the position $19.9 \mathrm{eV}$, as shown in Figure $14 \mathrm{a}$. The shift is caused by the Schottky barrier formation. The valence band of the bare and $\mathrm{Ni}$ film-covered GaN is presented in Figure $14 \mathrm{~b}$. It is clearly seen there that the VBM for the bare $\mathrm{GaN}(0001)$ is $2.8 \mathrm{eV}$, so for the initial surface it is above the Ga-3d line by $\Delta E=\mathrm{Ga}-3 \mathrm{~d}-\mathrm{VBM}=17.6$ $\mathrm{eV}$. After Ni deposition the Fermi edge is clearly visible, in the spectrum is the characteristic maximum with a BE equals $1.2 \mathrm{eV}$. The $\mathrm{SBH}$ can be simply calculated by the same procedure as applied for Mn films on GaN in the text above (section 2.2), as well as for Pd films on GaN [101].
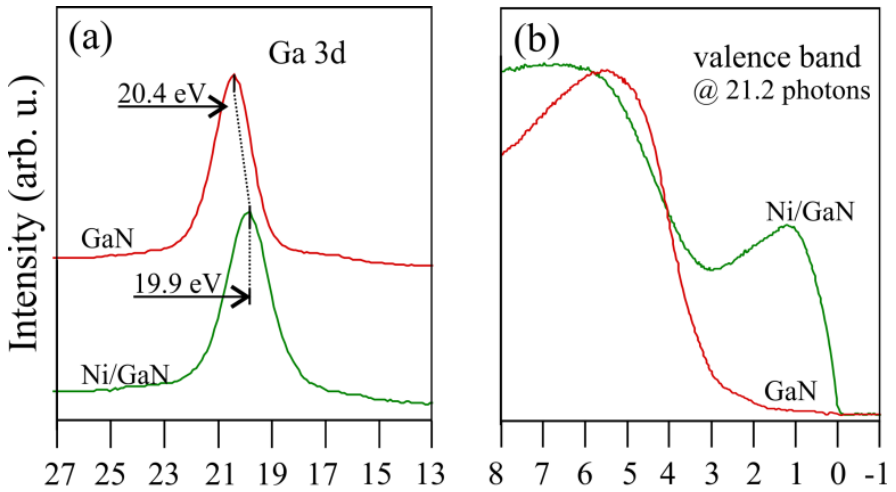

Binding Energy (eV)

Figure 14. Normalized spectra of (a) Ga-3d peaks and (b) valence band for bare and Ni film-covered $\mathrm{GaN}(0001)$ surface. Mean Ni film thickness is $3 \mathrm{~nm}$.

The formula is $\mathrm{SBH}_{\mathrm{GaN}}^{\mathrm{Ni}}=\mathrm{E}_{\mathrm{g}}-\mathrm{VBM}_{\mathrm{GaN}}^{\mathrm{Ni}}$, and the position of $\mathrm{VBM}_{\mathrm{GaN}}^{\mathrm{Ni}}=\mathrm{VBM}_{\mathrm{GaN}}-\left(\mathrm{Ga}_{\mathrm{G}} \mathrm{d}_{\mathrm{GaN}}-\right.$ $\left.\mathrm{Ga}_{\mathrm{G}} \mathrm{\textrm {Ni }}\right)=2.2 \mathrm{eV}$, giving the $\mathrm{SBH}=1.2 \mathrm{eV}$. The obtained value is consistent with literature, where the $\mathrm{SBH}$ is in the range from $0.95 \mathrm{eV}$ to $1.4 \mathrm{eV}$. The energy level diagrams of the bare and $\mathrm{Ni}$ film-covered $\mathrm{GaN}(0001)$ with the SBH constructed based on the UPS and XPS data is shown in Figure 15.
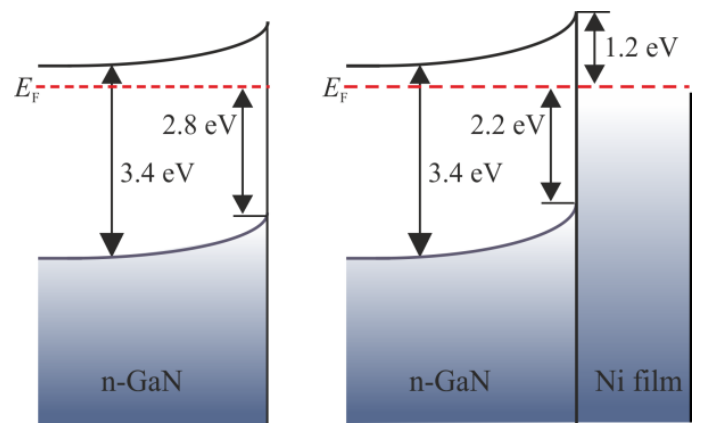

Figure 15. Energy band diagrams for Ni film-covered GaN(0001) surface.

The annealing of $\mathrm{Ni}$ films on $\mathrm{GaN}(0001)$ is interesting from a basic point of view to get a deep insight into the processes occurring on the interface, since this stage is often used in contact creation technology. Temperature treatment of the system by subsequent annealing at $650^{\circ} \mathrm{C}$ and then $800^{\circ} \mathrm{C}$ leads to a slight shift of the Ni-2p doublet towards a lower BE by $0.15 \mathrm{eV}$, reaching $870.25 \mathrm{eV}$ and $853.05 \mathrm{eV}$ for the Ni-2 $\mathrm{p}_{1 / 2}$ and $\mathrm{Ni}-2 \mathrm{p}_{2 / 3}$, respectively. The position of the shake-up satellite changes allowing to monitor $\mathrm{Ga}-\mathrm{Ni}$ intermixing phases at the surface. The satellite positions are $5.8 \mathrm{eV}, 6.2 \mathrm{eV}$ and $6.7 \mathrm{eV}$ below the parent peak for the non- and annealed surface at $650{ }^{\circ} \mathrm{C}$, followed by $800{ }^{\circ} \mathrm{C}$, respectively, are visible in Fig 16 . These relative positions of the satellite are characteristic of the $\mathrm{Ni}_{3} \mathrm{Ga}$ and $\mathrm{NiGa}$ or $\mathrm{Ni}_{3} \mathrm{Ga}_{2}$ alloys, respectively [102,103]. This does not imply that only these phases of Ga$\mathrm{Ni}$ alloys are presented in the film formed after annealing. It is, with high probability, not a homogeneous film and consists of different phases of alloys and metallic nickel. The results indicate the dominated phases in the film. 


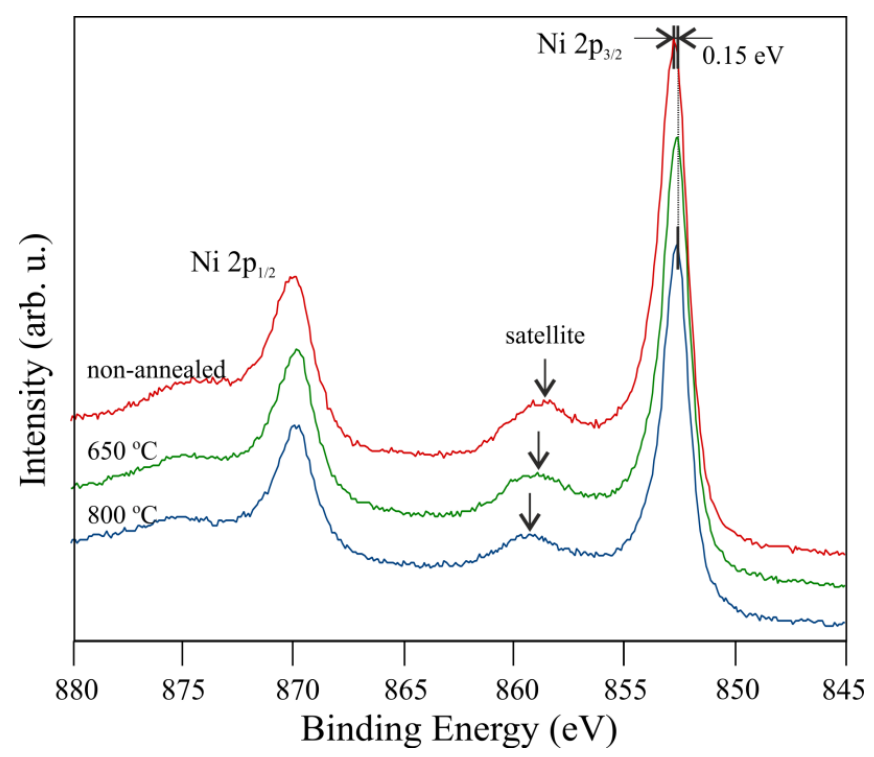

Figure 16. XPS spectra of Ni-2p for Ni film-covered GaN(0001) surface showing impact of annealing. Mean Ni film thickness is $3 \mathrm{~nm}$. (Data previously published in [29]).

Mixing Ni with Ga results from the fact that the latter atoms diffuse from the GaN subsurface layer into the adsorbed $\mathrm{Ni}$ film. The result of the intermixing of these two atoms is presented in Figure 17 a. The Ga-2p/2 peak splits into two sub-peaks. The sub-peaks at BEs of $1118.3 \mathrm{eV}$ and $1116.3 \mathrm{eV}$ are attributed to the Ga-N and Ga-Ni bonding. Further annealing at a higher temperature leads to a change in the intensity of the components. The Ga-N bond becomes more visible, indicating that the surface of the substrate is being partially uncovered. $\mathrm{Ni}$ atoms are not included into the subsurface layers of GaN, substitutional alloy is not formed. The system behaves differently than Mn films on $\mathrm{GaN}$ and the mixing appears only on the surface. In addition to temperature-induced changes in core level lines, the alterations also appear in the valence band, as shown in Figure $17 \mathrm{~b}$. The spectrum is strongly modified in comparison to the system not annealed. In the vicinity of the $E_{\mathrm{F}}$ are two features at $0.6 \mathrm{eV}$ and $0.9 \mathrm{eV}$. The DOS near the Fermi level for the sample after annealing at both temperatures are very similar. It is worth noting that for the system annealed at $800{ }^{\circ} \mathrm{C}$ the $\mathrm{VB}$ of the substrate became visible (marked by an arrow in Figure $17 \mathrm{~b}$ ), which is in line with the changes of the Ga-2p $3 / 2$ peak. The Fermi edge is similar to that obtained by XPS in [103], which is characteristic of $\mathrm{Ni}_{3} \mathrm{Ga}$ alloy. Therefore, UPS measurements only show one phase of Ni-Ga alloy regardless of annealing temperature (unlike XPS measurements of the Ni-2p line). Due to the fact that UPS is more surface sensitive than XPS, the results show that the $\mathrm{Ni}_{3} \mathrm{Ga}$ alloy is the most dominated phase on the top of the system surface. 


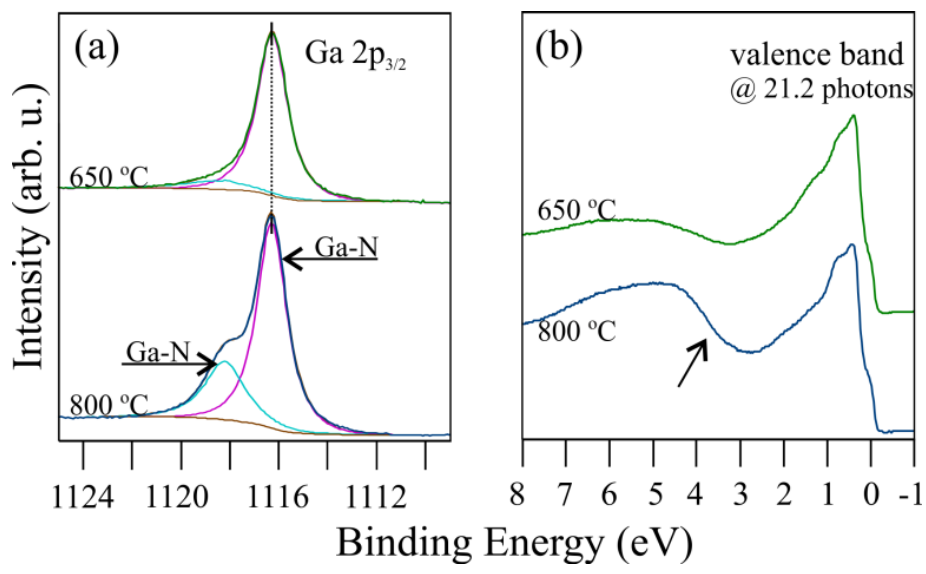

Figure 17. (a) XPS spectra of Ga-2p, and (b) UPS spectra of valence band for Ni film-covered $\mathrm{GaN}(0001)$ surface annealed at $650^{\circ} \mathrm{C}$ and $800^{\circ} \mathrm{C}$. Arrow indicates a visible DOS contribution from GaN. Mean film thickness is $3 \mathrm{~nm}$. (Data in (a) previously published in [29]).

Reconstruction on the surface after annealing is presented in Figure 18. LEED patterns from Ni film annealed at $650{ }^{\circ} \mathrm{C}$ show strong sharp spots corresponding to the $\mathrm{Ni}(111)-(\sqrt{3} \times \sqrt{3}) R 30^{\circ}$ structure with a lattice constant of $2.58 \AA$ and after annealing at $800{ }^{\circ} \mathrm{C}$ reveal sharp diffraction spots of the $\mathrm{Ni}(111)-(2 \times 2)$ and $\mathrm{GaN}(0001)-(1 \times 1)$ structures. The presence of spots corresponding to GaN $(0001)-$ (1×1) shows that further Ni-Ga alloying is accompanied by coalescence and, consequently, partial opening of the film and uncovering the substrate surface, which is consistent with the spectroscopic observations.
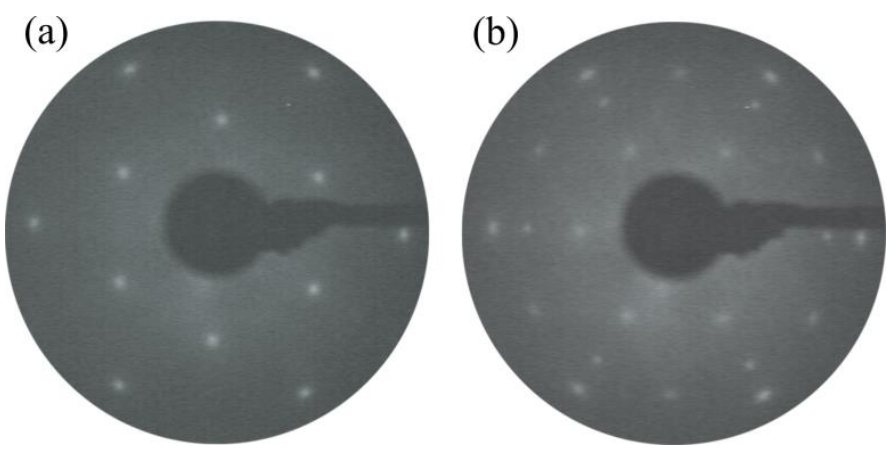

Figure 18. LEED patterns $(90 \mathrm{eV})$ for the $\mathrm{Ni}$ film-covered $\mathrm{GaN}(0001)$ after annealing at (a) $650{ }^{\circ} \mathrm{C}$ and (b) $800^{\circ} \mathrm{C}$. The three domains of the square structure of MnGa alloy and the $(1 \times 1)$ of the hexagonal structure of $\mathrm{GaN}(0001)$ substrate are marked. Mean film thickness is $3 \mathrm{~nm}$. (Data in previously published in [29]).

When semiconductors are exposed to photons with a higher energy than their forbidden gaps, electron-hole pairs are formed. That generation of an electron hole can also take place in metal/semiconductor systems, especially in the case of thin coating systems [104], and in consequence, may result in an appearance of a quasi-Fermi level. Such effect in the case of the Ni film on p-type $\mathrm{GaN}(0001)$ is described in Ref. [30] and presented below in the text. Evolutions of the Ga-3d and Ni$2 \mathrm{p}_{3 / 2}$ core level lines after $\mathrm{Ni}$ deposition on $\mathrm{p}$-type $\mathrm{GaN}(0001)$ surface follows by annealing are shown in Figure 19. The Ga-3d peak is located at a BE of $18.9 \mathrm{eV}$ for the bare $\mathrm{p}-\mathrm{GaN}(0001)$ surface and shifts towards a higher $\mathrm{BE}$ to the position $19.6 \mathrm{eV}$ after the $\mathrm{Ni}$ film deposition. According to the $\mathrm{Mn} / \mathrm{GaN}$ (section 2.2), as well as Ni/n-GaN systems described above in the text, it is obvious that the shift is related to the Schottky barrier formation. The $\mathrm{SBH}$ of $\mathrm{Ni}$ on $\mathrm{p}-\mathrm{GaN}$ for electrons is $\mathrm{SBH}_{\mathrm{pGaN}}^{\mathrm{Ni}}=\mathrm{E}_{\mathrm{g}}-$ $\mathrm{VBM}_{\mathrm{GaN}}^{\mathrm{Ni}}$, and the position of $\mathrm{VBM}_{\mathrm{GaN}}^{\mathrm{Ni}}=1.9 \mathrm{eV}$ (based on the Ga-3d shift), giving the $\mathrm{SBH}=1.5 \mathrm{eV}$. The value of $1.9 \mathrm{eV}$ is the magnitude of $\mathrm{SBH}$ for holes. However, after annealing of the system at $800^{\circ} \mathrm{C}$, the Ga-3d peak moves to its initial position, as shown in Figure 19 a, which is unusual. While the Ni- 
$2 \mathrm{p}_{3 / 2}$ core level line has a BE of $852.6 \mathrm{eV}$ for the as-deposed film and shifts by $1.0 \mathrm{eV}$ towards a lower $\mathrm{BE}$ following annealing, as shown in Figure $19 \mathrm{~b}$.

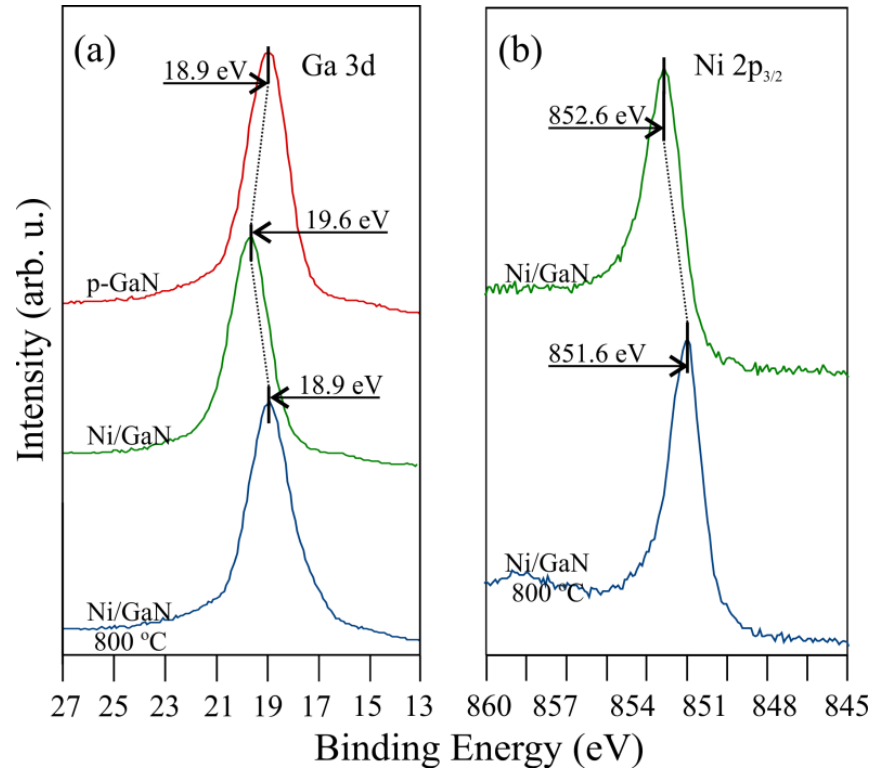

Figure 19. XPS spectra of (a) Ga $3 d$ and (b) Ni 2p $3 / 2$ for the bare and Ni film-covered p-GaN(0001) before and after annealing. Mean film thickness is $1 \mathrm{~nm}$. (Data previously published in [30]).

It would seem that such a large shift of the Ni line after annealing occurred as a result of a chemical reaction, however, as UPS measurements show, this interpretation is completely wrong. Spectra of the valence band for the bare and Ni film-covered p-GaN(0001) before and after annealing at $800{ }^{\circ} \mathrm{C}$ are shown in Figure 20. The VBM of the p-GaN sample is $1.2 \mathrm{eV}$ below the $E_{\mathrm{F}}$, which gives $\Delta E=\mathrm{Ga}-3 \mathrm{~d}-\mathrm{VBM}=17.7 \mathrm{eV}$. After the deposition of the thin Ni film of mean thickness of $1 \mathrm{~nm}$ a DOS nearby the $E_{\mathrm{F}}$ increases - the Fermi edge of the Ni film is clearly visible. The VB of the p-GaN is also noticeable in the spectrum, however shifted - its VBM now lies at $1.9 \mathrm{eV}$. This shift, similar as for the Ga-3d, is related to the electron charge transfer at the interface causing the Schottky barrier with a $\mathrm{SBH}$ for hole carriers amounts to the above value of $1.9 \mathrm{eV}$. After annealing, the VBM returns to the starting position, similarly to the Ga-3G peak behaviour. The DOS of the Ni film is still visible but above the Fermi level of energy analyzer - a quasi-Fermi level appeared at a BE of $-1.0 \mathrm{eV}$. The separation of the Fermi level in the substrate and the thin Ni film causes the shifts of the Ga-3d and $\mathrm{Ni}-2 \mathrm{p}_{3 / 2}$ core level line. The situation is well illustrated in Figure 21.

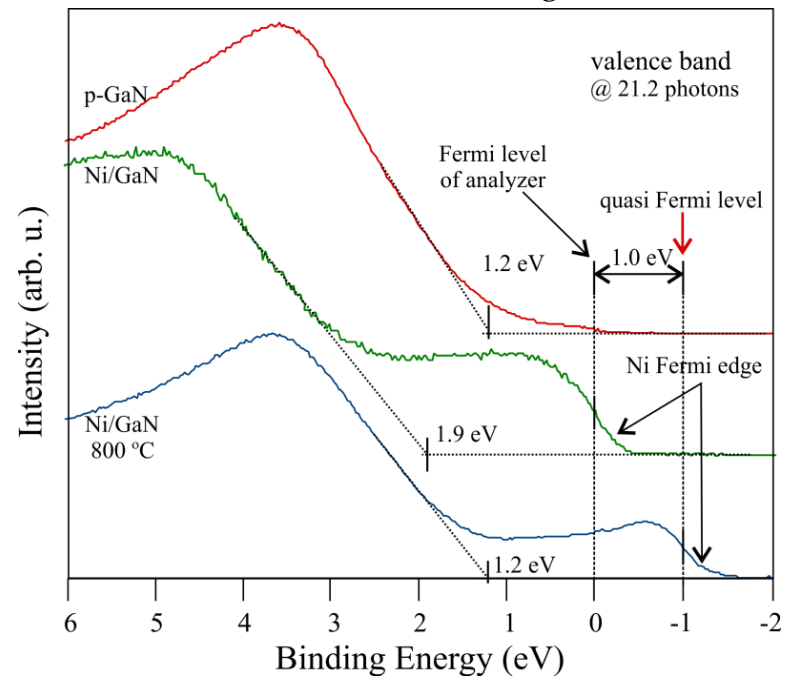

Figure 20. UPS spectra of the valence band for (a) bare, and Ni thin film-covered p-GaN(0001) surface (b) before and (c) after annealing. Mean film thickness is $1 \mathrm{~nm}$. (Data in previously published in [30]). 


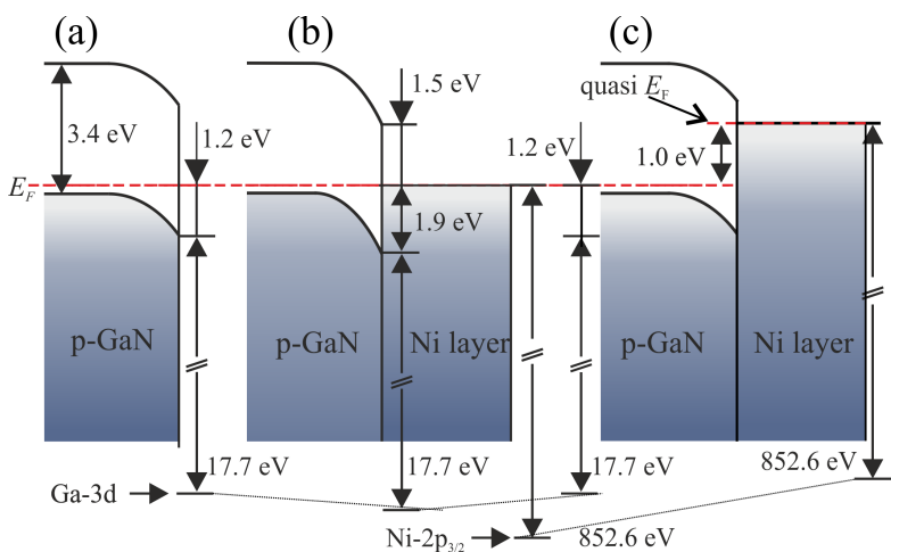

Figure 21. Band diagrams for (a) bare, and Ni thin film-covered p-GaN(0001) surface (b) before and (c) after annealing.

The presence of the quasi Fermi level follows from that the uncovering of the GaN surface after annealing exposes the phase boundary for illumination by photons whose energy is much higher than the forbidden gap of the GaN, resulting in electron-hole pairs being generated there. The p$\mathrm{GaN}(0001)$ surface is more negatively charged, compared to the system not annealed (Figure $21 \mathrm{~b}$ ), due to a holes transport from the nearby site of the interface to the grounded part of the sample. The $\mathrm{Ni}$ film-covered substrate after annealing is in the same condition as the bare surface (Figure $21 \mathrm{a}, \mathrm{c}$ ). Electrons from the valence band nearby the phase boundary are ejected into the conduction band of the substrate which is bent downwards, so there is no barrier for them from the metal film side, and they may flow down to the Ni film. Thus this part of the system is more negatively charged. The above text regarding $\mathrm{Ni}$ on $\mathrm{p}-\mathrm{GaN}$ is a good example, showing that some shifts of core level lines observed after annealing do not necessarily have to be the result of an interfacial chemical reaction and may be a consequence of other effects.

\subsection{As \& Sb on $G a N(0001)$}

Arsenic and antimony are semi-metals belonging to nitrite family, group V in the periodic table. Both these chemical elements exhibit poor electrical and thermal conductivity properties. Arsenic in crystal structure has poor metallic properties, however, in an amorphous form exhibits semiconductor properties and has a forbidden gap of $1.2 \mathrm{eV}$ [67]. As has a density of $5.75 \mathrm{~g} / \mathrm{cm}^{3}$, its thermal conductivity is $50 \mathrm{~W} /(\mathrm{m} \cdot \mathrm{K})$ and its electrical resistivity amounts to $3 \times 10^{-7} \Omega \cdot \mathrm{m}$ (at RT). It does not melt and starts to sublimate at $615{ }^{\circ} \mathrm{C}$ (under standard pressure). It easily evaporates in a vacuum starting at $107^{\circ} \mathrm{C}$ with a vapour pressure of $10^{-8} \mathrm{mbar}$ but in a form of various clusters. To eliminate this effect a special evaporation source with a cracker is needed. Antimony has a density of $6.69 \mathrm{~g} / \mathrm{cm}^{3}$, its thermal conductivity is $24 \mathrm{~W} /(\mathrm{m} \cdot \mathrm{K})$ and its electrical resistivity amounts to $4 \times 10^{-7} \Omega \cdot \mathrm{m}$ (at RT). It melts at $630{ }^{\circ} \mathrm{C}$ and its boiling point is $1635^{\circ} \mathrm{C}$ (both values refer to standard pressure). Like arsenic, antimony easily evaporates in a vacuum starting at $279^{\circ} \mathrm{C}$ with a vapour pressure of $10^{-8} \mathrm{mbar}$ and also in a form of various clusters. Both of these elements are used in the electronic industry as a part of semiconductor compound (e.g., GaAs, InSb) or as n-type dopants for semiconductor IV-group. Further, they were attempted to be used as surfactants to improve the quality of GaN layers grown by MBE [42-47] as well as to form new electronic materials such as $\mathrm{GaN}(\mathrm{As})$ and $\mathrm{GaN}(\mathrm{Sb})$ alloys. The introduction of $\mathrm{As}$ or $\mathrm{Sb}$ into $\mathrm{GaN}$ causes a modification of the electronic structure of the host material. Both elements cause narrowing of the forbidden gap, in addition, arsenic shifts the VB upwards [4854].

Surface study on the interaction of As with the GaN(0001) using XPS with monochromatic Al line and reflection of high-energy electron diffraction (RHEED) are described in the author's work [57]. The reason for this research is the potential use of arsenic as a means to modify the electronic properties of surfaces. The growth of As film by PVD with a cracker source and characterisation were 
performed in situ on non-doped MOCVD GaN(0001). The initial bare surface prepared by RTA reveals a very small amount of carbon (at the limit of XPS detection) and no oxide contaminant. RHEED exhibits sharp and bright diffraction patterns corresponding to the $(1 \times 1)$ structure (not shown). During the growth the signal of RHEED patterns decreases with an overlayer thickness of As films. For coatings equal to $2 \mathrm{~nm}$ and higher the patterns disappear completely suggesting that the film is amorphous. The Ga-3d, As-2 $\mathrm{p}_{3 / 2}$ core level lines and the valence band prior and after the deposition of the As film $\sim 5 \mathrm{~nm}$ thick are presented in Figure 22.
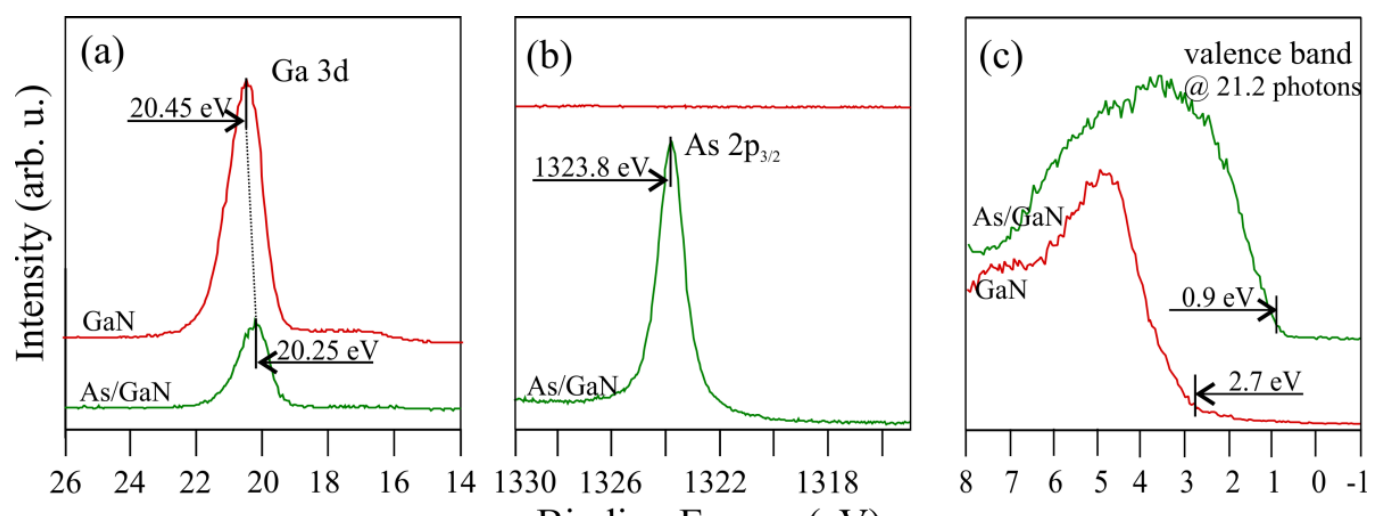

Binding Energy (eV)

Figure 22. XPS spectra of (a) Ga-3d, (b) As-2p $3 / 2$ and (c) UPS spectra of valence band for the bare and As film-covered GaN(0001). Mean film thickness is $\sim 5 \mathrm{~nm}$. (Data previously published in [57]).

After arsenic deposition on the bare $\mathrm{GaN}(0001)$ surface the Ga-3d core level line shifts towards a lower BE by $0.2 \mathrm{eV}$ to a position of $20.25 \mathrm{eV}$. The As-p23/2 emerges at a BE of $1323.3 \mathrm{eV}$ and corresponds to As-As bonds [105]. The valence band of the bare $\mathrm{GaN}(0001)$ surface is characteristic of typical non-doped GaN. The VBM lies $2.7 \mathrm{eV}$ below the $E_{\mathrm{F}}$ and the energetic distance from it to the Ga-3d state is $\Delta E=\mathrm{Ga}-3 \mathrm{~d}-\mathrm{VBM}=17.7 \mathrm{eV}$. The DOS of the As film does not start at the Fermi level, as shown in Figure $22 \mathrm{c}$. The edge is shifted towards a higher BE meaning that the amorphous layers have semiconductor character for which the VBM is $0.9 \mathrm{eV}$ below the $E_{\mathrm{F}}$. The shift of the Ga-3d peak, shown in Figure 22 a, is caused by electrons transfer at the interface, similar to the metal/GaN systems described above in the text (section 2.1 and 2.2). However, in this case, instead of SBH, the valence band offset $(\Delta E v)$ at the phase boundary can be estimated. It can be done basing on a method described in Ref. [106]. The formula is $\Delta E_{\mathrm{v}}=E_{\mathrm{V}-\mathrm{As} 2 \mathrm{p}}(\mathrm{As})-E_{\mathrm{V}-\mathrm{Gazd}}(\mathrm{GaN})-\Delta E_{\mathrm{As} 2 \mathrm{p}, \mathrm{Gazd}}$, where $E_{\mathrm{V}-\mathrm{As} 3 \mathrm{~d}}(\mathrm{As})$ and $E_{\mathrm{v}-\mathrm{Gazd}}(\mathrm{GaN})$ are the $\mathrm{Ga}-3 \mathrm{~d}$, the As-2p $3 / 2 \mathrm{~d}$ positions relative to the VBM of $\mathrm{GaN}$ and As film. Those values are $17.7 \mathrm{eV}$ and $1322.9 \mathrm{eV}$ and $\Delta E_{\mathrm{As} 3 \mathrm{~d}, \mathrm{Gazd}}$ is the energy difference between the $\mathrm{As}-2 \mathrm{p}_{3 / 2}$ and Ga$3 \mathrm{~d}$ levels when both peaks are visible after the As/GaN interface creation, it amounts to $1303.55 \mathrm{eV}$. The $\Delta E \mathrm{v}$ for the As/GaN interface is $1.65 \mathrm{eV}$. It means that the valence band of $\mathrm{As}$ is above the $\mathrm{VB}$ of $\mathrm{GaN}$ by that value. The conduction band offset $(\Delta E \mathrm{c})$ can be also evaluated with the formula $\Delta E_{\mathrm{c}}=$ $E_{\mathrm{g}}(\mathrm{As})+\Delta E \mathrm{v}-E_{\mathrm{g}}(\mathrm{GaN})$, where values of $1.2 \mathrm{eV}$ and $3.4 \mathrm{eV}$ are used for the forbidden gap of the As film [67] and GaN, respectively. The $\Delta E_{\mathrm{c}}=-0.55 \mathrm{eV}$. The '-' sign indicates that the conduction band of As is below that of the GaN. These values allow to construct an energy sketch for the As/GaN phase boundary, as shown in Figure 23. 


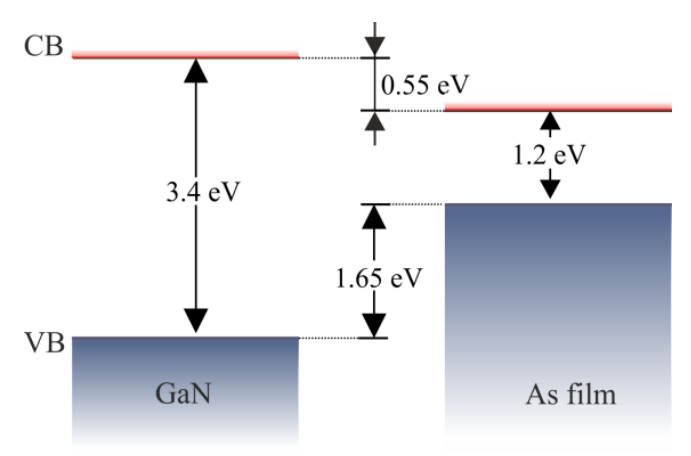

Figure 23. Bands diagram demonstrating valence and conduction band offsets for As film-covered GaN(0001) surface.

The relatively low As sublimation temperature under UHV conditions should make As easily escape from the surface of $\mathrm{GaN}$ (0001). Examination of the effect of temperature on the As/GaN system shows that annealing at temperatures below and equal to $200{ }^{\circ} \mathrm{C}$ does not introduce significant changes. The As- $2 p$ peak intensity decreases a bit after annealing at $200{ }^{\circ} \mathrm{C}$. This is surprising because at $200{ }^{\circ} \mathrm{C}$ arsenic has a relatively high vapour pressure of $10^{-4}$ mbar. After annealing at $300{ }^{\circ} \mathrm{C}$ As does not desorb completely from the surface. The As-2p/2 core level line shifts slightly from $1323.8 \mathrm{eV}$ to $1323.65 \mathrm{eV}$ and for temperatures in the range from $350^{\circ} \mathrm{C}$ to $500^{\circ} \mathrm{C}$ the peak shifts further, reaching the positions of $1323.3 \mathrm{eV}$, as shown in Figure 24. This indicates that there has been a chemical interaction of arsenic with the GaN(0001) surface. However, the As-2 $\mathrm{p}_{3 / 2}$ core level line lies at a higher BE than the As-Ga bonding. Therefore, it is possible that arsenic may interact with the surface in the form of As2, as considered in Ref. [44]. Repeating series (As deposition + annealing) does not create new surface alloys on $\mathrm{GaN}$ (0001), as in the case of the previously described Ni/GaN system (section 2.2) or the $\mathrm{Pd} / \mathrm{GaN}$ system [34]. The condition of the interface remains unchanged, i.e., the XPS lines from the substrate and the adsorbate do not change. In addition the amount of the fraction As2-GaN(0001) remains unchanged. It is due to the vapour pressure of the adsorbate being much higher than that of gallium (metallic gallium has a vapour pressure of $10^{-4}$ mbar at $900{ }^{\circ} \mathrm{C}$ ). So, arsenic atoms escape to vacuum and have no chance to react with the segregated gallium on the surface. An example of changes introduced in the valence band by annealing at $400{ }^{\circ} \mathrm{C}$ is shown in Figure $24 \mathrm{~b}$. The As film thickness for this stage is $0.25 \mathrm{~nm}$. Taking the As density, $1 \AA=4.62 \times 10^{14}$ $A s \cdot \mathrm{cm}^{-2}$ and one monolayer (ML) on $\mathrm{GaN}(0001)$ surface corresponds to a density of $1.14 \times 10^{15}$ atoms $\cdot \mathrm{cm}^{-2}$. This gives a coverage of As equal to $1 \mathrm{ML}$. This coverage also explains the lack of growth of the residual arsenic after the subsequent cycles (deposition + annealing) since there is no site where it could chemically interact with the $\mathrm{GaN}(0001)$ surface.

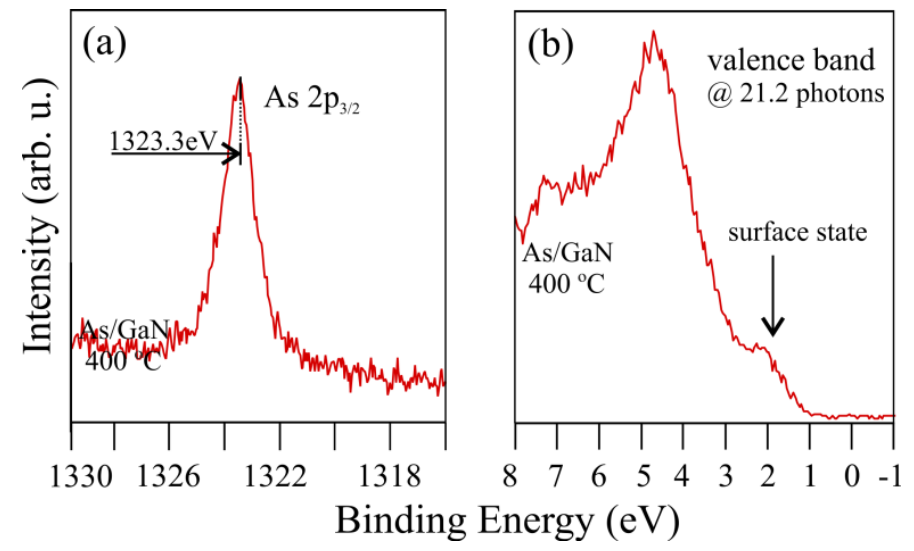

Figure 24. XPS spectra of (a) As-2p3/2 and (b) UPS spectra of valence band for the annealed As filmcovered $\mathrm{GaN}(0001)$ at $400{ }^{\circ} \mathrm{C}$. Amount of residual arsenic is $1 \mathrm{ML}$. (Data previously published in [57]). 
The surface DOS (SDOS) emerges at a position of $2.2 \mathrm{eV}$ below the Fermi level. Its highest occupied state is found to be at $1.05 \mathrm{eV}$. Further, the VBM for the system shifts upwards by $0.2 \mathrm{eV}$, compared to the bare surface, and lies 2.5 below the $E_{\mathrm{F}}$. For this stage of the experiment RHEED patterns exhibit the clear (1x1) structure and the Ga-3d is shifted to $20.3 \mathrm{eV}$. The energy diagrams constructed for the initial bare and As-modified GaN(0001) surfaces are presented in Figure 25.

(a)

(b)

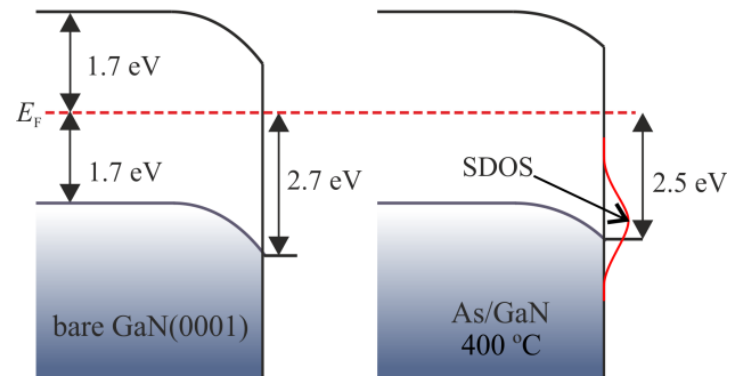

Figure 25. Energy diagrams for (a) bare $\mathrm{GaN}(0001)$ and (b) annealed As film-covered GaN(0001) surface at $400{ }^{\circ} \mathrm{C}$.

The SDOS is very well visible even for the system annealed to $500{ }^{\circ} \mathrm{C}$. Further annealing in a temperature range $600{ }^{\circ} \mathrm{C}-700{ }^{\circ} \mathrm{C}$ of the already annealed system reduces the amount of arsenic. However, it does not completely remove arsenic from the surface. At $700{ }^{\circ} \mathrm{C}$ the As- $2 \mathrm{p}_{3 / 2}$ line shifts to a BE of $1322.85 \mathrm{eV}$, which corresponds to As-Ga bonds in GaAs crystals $[105,107]$ revealing that arsenic atoms are no longer present at the surface as an As2. The residues of the SDOS can still be slightly distinguished in the valence band spectrum. So it proves that the SDOS is associated with As present on the GaN surface.

The interaction of $\mathrm{Sb}$ adsorber with the $\mathrm{GaN}(0001)$ surface and morphological changes caused by post-deposition annealing are studied in Ref. [58]. The growth of As film by PVD and the surface investigation were carried out in situ on Mg-doped, p-type, MOCVD GaN(0001) surface. The initial surface was prepared by annealing under UHV conditions. After that the clean surface reveals a very small amount of oxygen and no carbon (C KLL). LEED exhibits sharp and bright diffraction patterns corresponding to the $(1 \times 1)$ structure (similar to that in Figure 5 a). LEED does not show diffraction patterns for $\mathrm{Sb}$ films deposited at RT on the p-type $\mathrm{GaN}(0001)$ surface. It indicates that $\mathrm{Sb}$ layers are amorphous. For the bare surface the Ga-3d peak is located at $19.5 \mathrm{eV}$ and after deposition of the $\mathrm{Sb}$ film, $5 \mathrm{~nm}$ thick, the line shifts towards a higher BE to the position $20.5 \mathrm{eV}$, as shown in Figure $26 \mathrm{a}$. The Sb-4d core level line is located at a BE of $32 \mathrm{eV}$. The shift of Ga-3d results from the Schottky barrier formation. The VBs of the bare and $\mathrm{Sb}$ film-covered $\mathrm{GaN}(0001)$ surface are presented in Figure $26 \mathrm{~b}$. The VBM is located $1.5 \mathrm{eV}$ below the $E_{\mathrm{F}}$ for the bare $\mathrm{GaN}(0001)$, so it is above the Ga-3d peak by $\Delta E=\mathrm{Ga}-3 \mathrm{~d}-\mathrm{VBM}=17.6 \mathrm{eV}$. After $\mathrm{Sb}$ deposition the Fermi edge is clearly visible with a characteristic maximum at $1.6 \mathrm{eV}$, the spectrum is similar to that observed for $\mathrm{Sb} / \mathrm{SiC}$ system in Ref.[108]. 


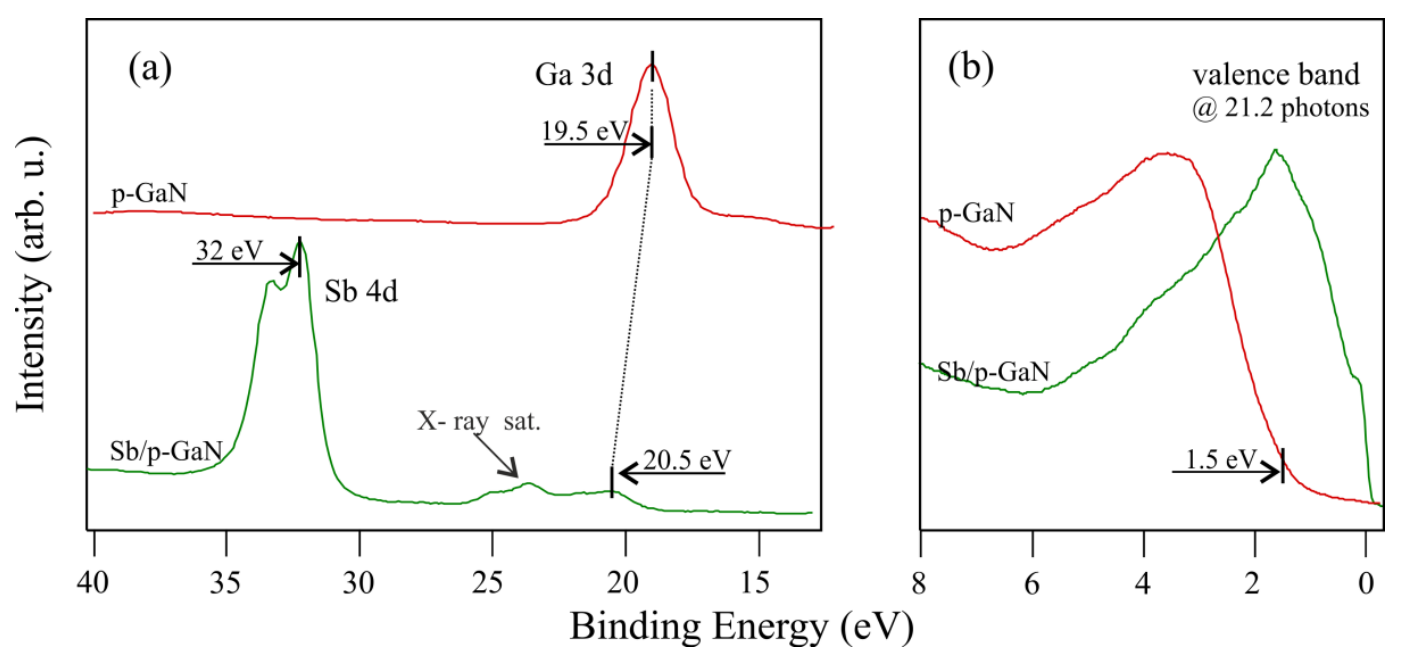

Figure 26. XPS spectra of (a) Ga-3d, Sb-3d and (b) UPS spectra of valence band for the bare and Sb film-covered $\mathrm{GaN}(0001)$. Mean thickness of film is $5 \mathrm{~nm}$. (Data previously published in [57]).

The SBH can be calculated by the same procedure as in the case of $\mathrm{Mn}$ or Ni films on $\mathrm{GaN}$ in the text above (section 2.2, 2.3). The $\mathrm{SBH}$ for electron is $\mathrm{SBH}_{\mathrm{GaN}}^{\mathrm{Sb}}=\mathrm{E}_{\mathrm{g}}-\mathrm{VBM}_{\mathrm{GaN}}^{\mathrm{Sb}}$, and the position of $\mathrm{VBM}_{\mathrm{GaN}}^{\mathrm{Sb}}=\mathrm{VBM}_{\mathrm{GaN}}-\left(\mathrm{Ga}_{\mathrm{G}} \mathrm{d}_{\mathrm{GaN}}-\mathrm{Ga}_{\mathrm{G}}^{\mathrm{GbN}}\right)=2.5 \mathrm{eV}$, giving the $\mathrm{SBH}=0.9 \mathrm{eV}$. While the value of $2.5 \mathrm{eV}$ it is the $\mathrm{SBH}$ for holes. The bands diagrams for the bare and $\mathrm{Sb}$ film-covered $\mathrm{GaN}(0001)$ are illustrated in Figure 27.

(a)

(b)

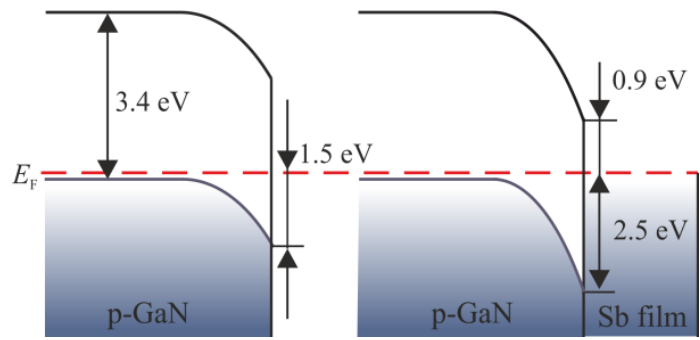

Figure 27. Bands diagram for (a) bare and (b) Sb film-covered GaN(0001) surface.

$\mathrm{Sb}$ atoms easily desorb from surfaces under UHV conditions, starting at about $280{ }^{\circ} \mathrm{C}$ [108]. So annealing of the $\mathrm{Sb} / \mathrm{GaN}$ system at $400{ }^{\circ} \mathrm{C}$ should lead to complete desorption of $\mathrm{Sb}$ atoms from the $\mathrm{GaN}(0001)$ surface. However, the investigation shows a presence of the Sb-3d peak in XPS spectrum. The position of the $\mathrm{Sb}-4 \mathrm{~d}$ remains unchanged relatively to the metallic $\mathrm{Sb}$, which may suggest no chemical interaction with the surface, however the $\mathrm{BE}$ of $32 \mathrm{eV}$ is characteristic of the Ga-Sb binding [109]. Considering the annealing temperature and the position of the Sb-4d, it all indicates that the residual As on the surface is rather in a chemical compound of $\mathrm{Ga}$. So the system under the influence of annealing behaves similarly to the As/GaN. The Ga-3d state shifts from $20.5 \mathrm{eV}$ towards a lower $\mathrm{BE}$ to $19.9 \mathrm{eV}$, as shown in Figure $28 \mathrm{a}$. The thickness of the residual $\mathrm{Sb}$ film is $0.25 \mathrm{~nm}$. Taking the $\mathrm{Sb}$ density, $1 \AA=3.31 \times 10^{14} \mathrm{Sb} \cdot \mathrm{cm}^{-2}$, this gives a coverage of Sb equal to $\sim 0.7 \mathrm{ML}$. UPS spectrum shows a restoration of the valence band of a semiconductor type, with no sign of DOS unlike in the case of $\mathrm{As} / \mathrm{GaN}$ system. The VBM lies at $1.6 \mathrm{eV}$ below the $E_{\mathrm{F}}$, as shown in Figure $28 \mathrm{~b}$. In addition to changes in the VBM, the small amount of As strongly modifies the vacuum level, which is smaller by $1.2 \mathrm{eV}$ compared to the bare surface [57]. 


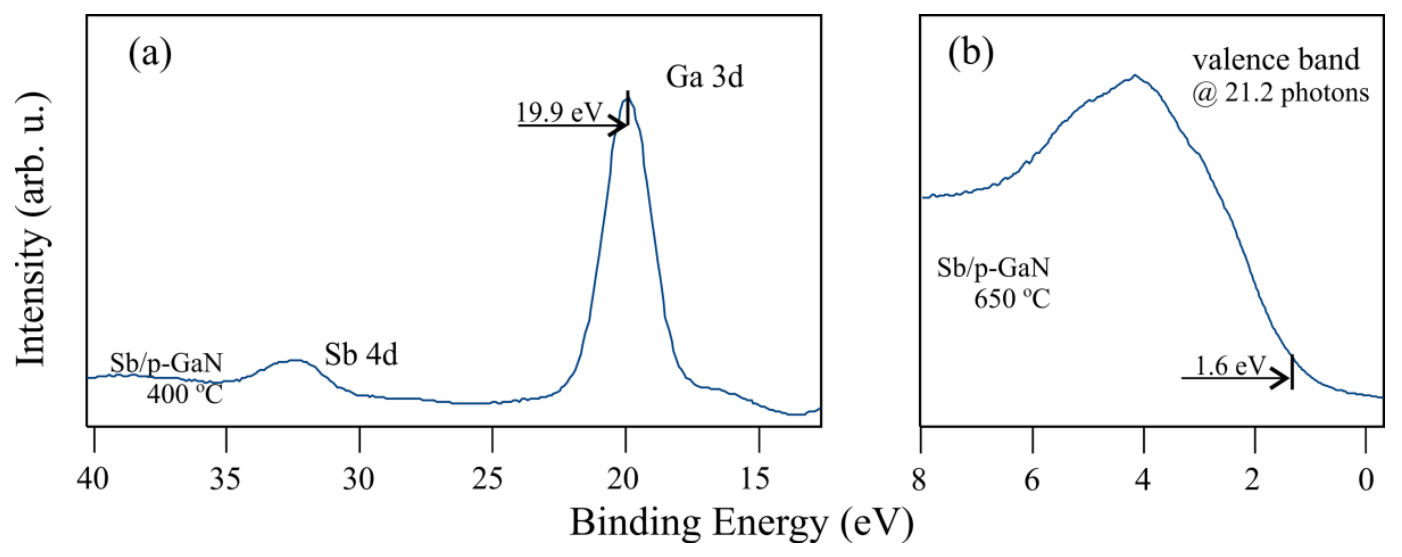

Figure 28. XPS spectra of (a) Ga-3d, Sb-3d and (b) UPS spectra of valence band for annealed Sb filmcovered $\mathrm{GaN}(0001)$ surface at $400{ }^{\circ} \mathrm{C}$. Amount of residual arsenic is $\sim 0.7 \mathrm{ML}$. (Data previously published in [57]).

\section{Summary}

Photoelectron spectroscopies (XPS, UPS) were used to investigate properties of bare and filmcovered $\mathrm{GaN}(0001)$ surfaces.

The bare $\mathrm{GaN}(0001)$ was characterized with different X-ray excitation sources, i.e., nonmonochromatic $\mathrm{Mg} K_{\alpha}(1253.6 \mathrm{eV})$, non- and monochromatic $\mathrm{Al} K_{\alpha}(1486.7 \mathrm{eV})$. Their influence on the shapes of the core level lines and valence band are found. The type of X-ray source has a particularly large impact on the shape of the N-1s line due to the overlap of the Auger lines that occur for photons with an energy of $1487.7 \mathrm{eV}$. Significant changes are also observed in the valence band, caused by overlapping with X-ray satellites in the case of non-monochromatic sources. Binding energy positions of Auger lines vs. X-ray sources are shown. Electronic properties of non- and various doped $\mathrm{GaN}(0001)$ surfaces studied by UPS are presented. The valence band maxima lie $2.7 \mathrm{eV}$ below the Fermi level for non-doped GaN and in the case of doped materials they are at $3.1 \mathrm{eV}, 1.5 \mathrm{eV}$ for the $\mathrm{n}$ - and p-type semiconductor, respectively.

Physical and chemical properties of thin films on $\mathrm{GaN}(0001)$, including several elements: manganese, nickel, arsenic and antimony were described. Photoelectron spectroscopies were also employed to determine the Schottky barrier height at the formed interfaces. The systems were created in situ on the substrates cleaned by annealing under UHV conditions and adsorbates were evaporated from a Knudsen-like cells. No evidence of epitaxial growth of the films at RT was found.

The investigation of manganese films on $\mathrm{GaN}(0001)$ shows that the Schottky barrier height of the interface amounts to $1.20 \mathrm{eV}$. A chemical interaction of Mn atoms with the substrate at RT is excluded. Annealing the system results in morphological changes. Mn atoms and Ga intermix at the interface. Two effects are found: (i) segregated Ga atoms diffuse into Mn, forming MnGa surface alloy; (ii) Mn atoms move in the opposite direction, toward the inside the substrate, and consequently form (Mn, Ga)N-like alloy. MnGa surface alloy stays on the $\mathrm{GaN}(0001)$ after annealing up to $800^{\circ} \mathrm{C}$, achieving a domain structure epitaxially oriented relatively to the $\mathrm{GaN}(0001)$ substrate. Annealing at a higher temperature can result in removing the MnGa adlayer, but the effect of replacing gallium with manganese atoms in the sublayers of $\mathrm{GaN}$ is still visible. It leads to a strong modification of the valence band. The valence band maximum of $\mathrm{p}-\mathrm{GaN}$ after thermal desorption of the MnGa surface alloy is strongly shifted upwards from $1.5 \mathrm{eV}$ to $0.1 \mathrm{eV}$. This result is promising as a stage of preparation of the substrate for Ohmic contacts with $\mathrm{p}-\mathrm{GaN}$.

The studies on nickel films on GaN(0001) surfaces show that the Schottky barrier height of the interface with n-type semiconductor amounts to $1.20 \mathrm{eV}$ and with p-type is $1.5 \mathrm{and} 1.9 \mathrm{eV}$ for electron and holes, respectively. Annealing the $\mathrm{Ni} / \mathrm{GaN}$ interface causes uncovering of the substrate surface. A coalescence of grainy Ni films occurs. Moreover Ni-Ga surface alloying is exhibited. Ga diffuses into a $\mathrm{Ni}$ film and intermix with it. $\mathrm{Ni}_{3} \mathrm{Ga}$ is found as the dominant alloying phase. Further annealing 
at a higher temperature leads to the formation of more Ga-rich alloy phase. It is recognized as NiGa or $\mathrm{Ni}_{3} \mathrm{Ga}$.

The Ni/p-GaN interface investigation revealed that the XPS, UPS measurements themselves may affect the electronic structure of the system. Surface conditions of the system were found in which electrons ejected by X-rays or UV penetrate into the metal part of the interface, leading to the film being charged, the consequence of which is the appearance of quasi-Fermi level and shifting the film's core level lines. This result is a good example of that some shifts of XPS peaks observed after annealing metal/semiconductor systems may be a consequence of other effects than chemical interactions. Therefore, to explain the reason for this shift, core level measurements are insufficient and electrons from a valence band should also be monitored.

The study of arsenic films on $\mathrm{GaN}(0001)$ shows that the amorphous films exhibit a semiconductor character. The valence band offset is determined to be $1.65 \mathrm{eV}$ and the conduction band offset is $-0.55 \mathrm{eV}$ relatively to the conduction band of the substrate. A chemical interaction of As atoms with the substrate at RT is excluded. Annealing the system results in an arsenic desorption, however not completely. The residual As atoms are chemically interacted with the GaN(0001) surface, probably in the form of As2-Ga. Further annealing at a higher temperature causes that the As remainders are supposed to be chemically reacted with the surface in the form of As-Ga. The presence of As atoms at the $\mathrm{GaN}(0001)$ surface causes a modification of the valence band - SDOS appears.

The investigation of antimony films on $\mathrm{p}-\mathrm{GaN}(0001)$ shows that the Schottky barrier height of the interface is $0.9 \mathrm{eV}$ and $2.50 \mathrm{eV}$ for electrons and holes, respectively. The annealing of the system causes an antimony desorption, however, as in the $\mathrm{As} / \mathrm{GaN}$ system, $\mathrm{Sb}$ atoms are not completely removed. Despite the lack of shift of the $\mathrm{Sb}-4 \mathrm{~d}$, it is assumed that residual $\mathrm{Sb}$ atoms might be reacted with the substrate since the temperature is too high for metallic $\mathrm{Sb}$ atoms to survive on the surface.

Acknowledgments: The work was supported by the University of Wrocław. Some results shown in this paper were obtained as part of the project FNP - Team Tech/2016-3/16 carried out at PORT. The author would like to thank all the scientists with whom he had the opportunity to cooperate on the topics presented in this work. The author would also like to thank A. Sabik and K. Świstak for correcting the manuscript.

\section{References}

1. Doverspike, K.; Pankove, J. Chapter 9 Doping in the III-Nitrides. In Future Directions in Silicon Photonics; Elsevier BV, 1997; Vol. 50, pp. 259-277.

2. Nakamura, S.; Senoh, M.; Mukai, T. Highly P-Typed Mg-Doped GaN Films Grown with GaN Buffer Layers. Jpn. J. Appl. Phys. 1991, 30, L1708-L1711, doi:10.1143/jjap.30.11708.

3. Nakamura, S.; Mukai, T.; Senoh, M.; Iwasa, N. Thermal Annealing Effects on P-Type Mg-Doped GaN Films. Jpn. J. Appl. Phys. 1992, 31, L139-L142, doi:10.1143/jjap.31.1139.

4. Khan, M.A.; Chen, Q.; Shur, M.S.; Dermott, B.; Higgins, J.; Burm, J.; Schaff, W.; Eastman, L. GaN based heterostructure for high power devices. Solid-state Electron. 1997, 41, 1555-1559, doi:10.1016/s00381101(97)00104-4.

5. T. Yao, S.-K. Hong, eds., Oxide and Nitride Semiconductors: Processing, Properties, and Applications, Springer-Verlag, Berlin Heidelberg, 2009. //www.springer.com/us/book/9783540888468 (accessed January 24, 2019).

6. Flack, T.J.; Pushpakaran, B.; Bayne, S.B. GaN Technology for Power Electronic Applications: A Review. J. Electron. Mater. 2016, 45, 2673-2682, doi:10.1007/s11664-016-4435-3.

7. Qian, H.; Lee, K.; Vajargah, S.H.; Novikov, S.; Guiney, I.; Zaidi, Z.; Jiang, S.; Wallis, D.; Foxon, C.; Humphreys, C.; et al. Novel GaN-based vertical heterostructure field effect transistor structures using crystallographic $\mathrm{KOH}$ etching and overgrowth. J. Cryst. Growth 2017, 459, 185-188, doi:10.1016/j.jcrysgro.2016.12.025.

8. Medjdoub, F.; Iniewski, K. Gallium Nitride ( $G a N)$; Informa UK Limited, 2017;

9. K. Mochizuki, Vertical GaN and SiC Power Devices, Artech House, 2018.

10. Coffie, R.L. High Power High Frequency Transistors: A Material's Perspective. In High-Frequency GaN Electronic Devices; Springer Science and Business Media LLC, 2019; pp. 5-41. 
11. Janicki, L.; Kunert, G.; Sawicki, M.; Piskorska-Hommel, E.; Gas, K.; Jakiela, R.; Hommel, D.; Kudrawiec, R. Fermi level and bands offsets determination in insulating (Ga,Mn)N/GaN structures. Sci. Rep. 2017, 7, 41877, doi:10.1038/srep41877.

12. Gas, K.; Domagala, J.Z.; Jakieła, R.; Kunert, G.; Dluzewski, P.; Piskorska-Hommel, E.; Paszkowicz, W.; Sztenkiel, D.; Winiarski, M.J.; Kowalska, D.; et al. Impact of substrate temperature on magnetic properties of plasma-assisted molecular beam epitaxy grown (Ga,Mn)N. J. Alloy. Compd. 2018, 747, 946-959, doi:10.1016/j.jallcom.2018.03.056.

13. Pearton, S.J.; Abernathy, C.; Norton, D.; Hebard, A.F.; Park, Y.; Boatner, L.A.; Budai, J.D. Advances in wide bandgap materials for semiconductor spintronics. Mater. Sci. Eng. R: Rep. 2003, 40, 137-168, doi:10.1016/s0927-796x(02)00136-5.

14. Dietl, T.; Ohno, H. Dilute ferromagnetic semiconductors: Physics and spintronic structures. Rev. Mod. Phys. 2014, 86, 187-251, doi:10.1103/revmodphys.86.187.

15. Qi, Y.; Sun, G.F.; Weinert, M.; Li, L. Electronic structures of Mn-induced phases on GaN(0001). Phys. Rev. B 2009, 80, 235323, doi:10.1103/physrevb.80.235323.

16. Wang, K.; Takeuchi, N.; Chinchore, A.V.; Lin, W.; Liu, Y.; Smith, A.R. Two-dimensional Mn structure on the GaN growth surface and evidence for room-temperature spin ordering. Phys. Rev. B 2011, 83, 165407, doi:10.1103/physrevb.83.165407.

17. Cui, Y.; Li, L. A $(10 \times 10)$ domain wall structure induced by Mn adsorption on the pseudo- $(1 \times 1)$ surface of GaN(). Surf. Sci. 2003, 522, L21-L26, doi:10.1016/s0039-6028(02)02400-7.

18. Dumont, J.; Kowalski, B.; Pietrzyk, M.; Seldrum, T.; Houssiau, L.; Douhard, B.; Grzegory, I.; Porowski, S.; Sporken, R. Atomically flat GaMnN by diffusion of Mn into GaN(). Superlattices Microstruct. 2006, 40, 607611, doi:10.1016/j.spmi.2006.07.028.

19. Chinchore, A.; Wang, K.; Shi, M.; Liu, Y.; Smith, A.R. Spontaneous formation of quantum height manganese gallium islands and atomic chains on N-polar gallium nitride(0001). Appl. Phys. Lett. 2012, 100, 61602, doi:10.1063/1.3682487.

20. Kowalik, I.A.; Kowalski, B.; Orlowski, B.; Lusakowska, E.; Iwanowski, R.; Mickevičius, S.; Johnson, R.; Grzegory, I.; Porowski, S. Photoemission study of Mn/GaN. Surf. Sci. 2004, 566, 457-461, doi:10.1016/j.susc.2004.05.085.

21. Hwang, J.I.; Osafune, Y.; Kobayashi, M.; Ebata, K.; Ooki, Y.; Ishida, Y.; Fujimori, A.; Takeda, Y.; Okane, T.; Saitoh, Y.; et al. Depth profile high-energy spectroscopic study of Mn-doped GaN prepared by thermal diffusion. J. Appl. Phys. 2007, 101, 103709, doi:10.1063/1.2732679.

22. Grodzicki, M.; Mazur, P.; Krupski, A.; Ciszewski, A. Studies of early stages of Mn/GaN(0001) interface formation using surface-sensitive techniques. Vac. 2018, 153, 12-16, doi:10.1016/j.vacuum.2018.03.059.

23. Grodzicki, M.; Mazur, P.; Brona, J.; Ciszewski, A. MnGa and (Mn,Ga)N-like alloy formation during annealing of Mn/GaN(0001) interface. Appl. Surf. Sci. 2019, 481, 790-794, doi:10.1016/j.apsusc.2019.03.121.

24. Grodzicki, M.; Mazur, P.; Sabik, A. Electronic properties of p-GaN co-doped with Mn by thermal process: Surface studies. Surf. Sci. 2019, 689, 121460, doi:10.1016/j.susc.2019.121460.

25. Bermudez, V.M.; Kaplan, R.; Khan, M.A.; Kuznia, J.N. Growth of thin Ni films on GaN(0001)-(1×1). Phys. Rev. B 1993, 48, 2436-2444, doi:10.1103/physrevb.48.2436.

26. Schmitz, A.C.; Ping, A.T.; Khan, M.A.; Chen, Q.; Yang, J.W.; Adesida, I. Schottky barrier properties of various metals on n-type GaN. Semicond. Sci. Technol. 1996, 11, 1464-1467, doi:10.1088/0268-1242/11/10/002.

27. Schmitz, A.; Ping, A.; Adesida, I.; Khan, M.A. Schottky Barrier Heights of Ni, Pt, Pd, and Au on n-type GaN. MRS Proc. 1995, 395, 831-835.

28. Rickert, K.A.; Ellis, A.; Kim, J.K.; Lee, J.-L.; Himpsel, F.J.; Dwikusuma, F.; Kuech, T.F. X-ray photoemission determination of the Schottky barrier height of metal contacts to $\mathrm{n}-\mathrm{GaN}$ and $\mathrm{p}-\mathrm{GaN}$. J. Appl. Phys. 2002, 92, 6671-6678, doi:10.1063/1.1518129.

29. Grodzicki, M.; Mazur, P.; Zuber, S.; Perš, J.; Brona, J.; Ciszewski, A. Effect of annealing on Ni/GaN(0001) contact morphology. Appl. Surf. Sci. 2014, 304, 24-28, doi:10.1016/j.apsusc.2014.01.023.

30. M. Grodzicki, P. Mazur, A. Sabik, Impact of surface photovoltage on photoemission from Ni/p-GaN, Applied Surface Science. 2020, 512, 145643, doi:10.1016/j.apsusc.2020.145643.

31. Greco, G.; Iucolano, F.; Roccaforte, F. Ohmic contacts to Gallium Nitride materials. Appl. Surf. Sci. 2016, 383, 324-345, doi:10.1016/j.apsusc.2016.04.016. 
32. Wang, W.; Xie, W.; Deng, Z.; Yang, H.; Liao, M.; Li, J.; Luo, X.; Sun, S.; Zhao, D. Performance Improvement of GaN Based Laser Diode Using Pd/Ni/Au Metallization Ohmic Contact. Coatings 2019, 9, 291, doi:10.3390/coatings9050291.

33. Li, M.; Li, C.; Wang, F.; Zhang, W. The thermodynamic analysis of the driving force for the Ni/GaN interfacial reaction. Mater. Sci. Eng. A 2006, 422, 316-320, doi:10.1016/j.msea.2006.02.017.

34. Grodzicki, M.; Mazur, P.; Perš, J.; Brona, J.; Zuber, S.; Ciszewski, A. Formation of GaPd2 and GaPd intermetallic compounds on GaN(0001). Appl. Phys. A 2015, 120, 1443-1451, doi:10.1007/s00339-015-9331-9.

35. Sharafutdinov, I.; Elkjær, C.F.; De Carvalho, H.W.P.; Gardini, D.; Chiarello, G.L.; Damsgaard, C.D.; Wagner, J.B.; Grunwaldt, J.-D.; Dahl, S.; Chorkendorff, I. Intermetallic compounds of Ni and Ga as catalysts for the synthesis of methanol. J. Catal. 2014, 320, 77-88, doi:10.1016/j.jcat.2014.09.025.

36. Studt, F.; Sharafutdinov, I.; Abild-Pedersen, F.; Elkjær, C.F.; Hummelshøj, J.S.; Dahl, S.; Chorkendorff, I.; Nørskov, J.K. Discovery of a Ni-Ga catalyst for carbon dioxide reduction to methanol. Nat. Chem. 2014, 6, 320-324, doi:10.1038/nchem.1873.

37. Kovnir, K.; Armbrüster, M.; Teschner, D.; Venkov, T.; Jentoft, F.; Knop-Gericke, A.; Grin, Y.; Schlögl, R. A new approach to well-defined, stable and site-isolated catalysts. Sci. Technol. Adv. Mater. 2007, 8, 420-427, doi:10.1016/j.stam.2007.05.004.

38. Osswald, J.; Giedigkeit, R.; Jentoft, R.; Armbrüster, M.; Girgsdies, F.; Kovnir, K.; Ressler, T.; Grin, Y.; Schlögl, R. Palladium-gallium intermetallic compounds for the selective hydrogenation of acetylenePart I: Preparation and structural investigation under reaction conditions. J. Catal. 2008, 258, 210-218, doi:10.1016/j.jcat.2008.06.013.

39. Osswald, J.; Kovnir, K.; Armbrüster, M.; Giedigkeit, R.; Jentoft, R.E.; Wild, U.; Grin, Y.; Schlögl, R. Palladium-gallium intermetallic compounds for the selective hydrogenation of acetylenePart II: Surface characterization and catalytic performance. J. Catal. 2008, 258, 219-227, doi:10.1016/j.jcat.2008.06.014.

40. Kovnir, K.; Armbrüster, M.; Teschner, D.; Venkov, T.; Szentmiklósi, L.; Jentoft, F.; Knop-Gericke, A.; Grin, Y.; Schlögl, R. In situ surface characterization of the intermetallic compound PdGa - A highly selective hydrogenation catalyst. Surf. Sci. 2009, 603, 1784-1792, doi:10.1016/j.susc.2008.09.058.

41. Armbrüster, M.; Schlögl, R.; Grin, Y. Intermetallic compounds in heterogeneous catalysis - a quickly developing field. Sci. Technol. Adv. Mater. 2014, 15, 34803, doi:10.1088/1468-6996/15/3/034803.

42. Foxon, C.; Cheng, T.; Novikov, S.; Jeffs, N.; Hughes, O.; Melnik, Y.; E Nikolaev, A.; Dmitriev, V. Galliuminduced surface reconstruction patterns of GaN grown by molecular beam epitaxy. Surf. Sci. 1999, 421, 377385, doi:10.1016/s0039-6028(98)00867-x.

43. Hughes, O.; Cheng, T.; Novikov, S.; Foxon, C.; Korakakis, D.; Jeffs, N. RHEED studies of the GaN surface during growth by molecular beam epitaxy. J. Cryst. Growth 1999, 201, 388-391, doi:10.1016/s00220248(98)01354-2.

44. Ramachandran, V.; Lee, C.; Feenstra, R.M.; Smith, A.; Northrup, J.; Greve, D. Structure of clean and arseniccovered GaN(0001) surfaces. J. Cryst. Growth 2000, 209, 355-363, doi:10.1016/s0022-0248(99)00570-9.

45. Vézian, S.; Semond, F.; Massies, J.; Bullock, D.; Ding, Z.; Thibado, P. Origins of GaN(0001) surface reconstructions. Surf. Sci. 2003, 541, 242-251, doi:10.1016/s0039-6028(03)00950-6.

46. Pei, C.W.; Turk, B.; Héroux, J.B.; Wang, W.I. GaN grown by molecular beam epitaxy with antimony as surfactant. J. Vac. Sci. Technol. B: Microelectron. Nanometer Struct. 2001, 19, 1426, doi:10.1116/1.1374627.

47. Gokhale, A.A.; Kuech, T.F.; Mavrikakis, M. Surfactant effect of Sb on GaN growth. J. Cryst. Growth 2005, 285, 146-155, doi:10.1016/j.jcrysgro.2005.08.021.

48. Shan, W.; Ager, J.W.; Yu, K.; Walukiewicz, W.; Haller, E.E.; Martín, M.C.; McKinney, W.R.; Yang, W. Dependence of the fundamental band gap of AlxGa1-xN on alloy composition and pressure. J. Appl. Phys. 1999, 85, 8505-8507, doi:10.1063/1.370696.

49. J. Wu, W. Walukiewicz, K.M. Yu, J.D. Denlinger, W. Shan, J.W. Ager, A. Kimura, H.F. Tang, T.F. Kuech, Valence band hybridization in N-rich $\mathrm{GaN}(1-\mathrm{x}) \mathrm{As}(\mathrm{x})$ alloys. Phys. Rev. B. 2004, 70, 115214. doi: 10.1103/PhysRevB.70.115214.

50. Zdanowicz, E.; Ciechanowicz, P.; Opołczyńska, K.; Majchrzak, D.; Rousset, J.-G.; Piskorska-Hommel, E.; Grodzicki, M.; Komorowska, K.; Serafinczuk, J.; Hommel, D.; et al. As-related stability of the band gap temperature dependence in N-rich GaNAs. Appl. Phys. Lett. 2019, 115, 092106, doi:10.1063/1.5110245.

51. Grodzicki, M.; Rousset, J.-G.; Ciechanowicz, P.; Piskorska-Hommel, E.; Hommel, D. XPS studies on the role of arsenic incorporated into GaN. Vac. 2019, 167, 73-76, doi:10.1016/j.vacuum.2019.05.043. 
52. Yu, K.; Sarney, W.L.; Novikov, S.; Detert, D.; Zhao, R.; Denlinger, J.D.; Svensson, S.; Dubon, O.D.; Walukiewicz, W.; Foxon, C. Highly mismatched N-rich GaN1-xSbx films grown by low temperature molecular beam epitaxy. Appl. Phys. Lett. 2013, 102, 102104, doi:10.1063/1.4795446.

53. Yu, K.; Novikov, S.; Ting, M.; Sarney, W.L.; Svensson, S.; Shaw, M.; Martin, R.W.; Walukiewicz, W.; Foxon, C. Growth and characterization of highly mismatched GaN1-xSbx alloys. J. Appl. Phys. 2014, 116, 123704, doi:10.1063/1.4896364.

54. Segercrantz, N.; Yu, K.; Ting, M.; Sarney, W.L.; Svensson, S.; Novikov, S.; Foxon, C.; Walukiewicz, W. Electronic band structure of highly mismatched GaN1-xSbx alloys in a broad composition range. Appl. Phys. Lett. 2015, 107, 142104, doi:10.1063/1.4932592.

55. Thao, C.P.; Tuan, T.T.A.; Kuo, D.-H.; Ke, W.-C.; Na Thach, T.V.S.; Cao, P.T. Reactively Sputtered Sb-GaN Films and its Hetero-Junction Diode: The Exploration of the n-to-p Transition. Coatings 2020, 10, 210, doi:10.3390/coatings10030210.

56. Segercrantz, N.; Baumgartner, Y.; Ting, M.; Yu, K.; Mao, S.S.; Sarney, W.L.; Svensson, S.; Walukiewicz, W. Undoped p-type GaN1-xSbx alloys: Effects of annealing. Appl. Phys. Lett. 2016, 109, 252102, doi:10.1063/1.4972559.

57. Grodzicki, M.; Rousset, J.-G.; Ciechanowicz, P.; Piskorska-Hommel, E.; Hommel, D. Surface studies of physicochemical properties of As films on GaN(0001). Appl. Surf. Sci. 2019, 493, 384-388, doi:10.1016/j.apsusc.2019.07.006.

58. Grodzicki, M.; Mazur, P.; Pers, J.; Zuber, S.; Ciszewski, A. Sb Layers on p-GaN: UPS, XPS and LEED Study. Acta Phys. Pol. A 2014, 126, 1128-1130, doi:10.12693/aphyspola.126.1128.

59. Feenstra, R.M.; Northrup, J.E.; Neugebauer, J. Review of Structure of Bare and Adsorbate-Covered GaN(0001) Surfaces. MRS Internet J. Nitride Semicond. Res. 2002, 7, doi:10.1557/S1092578300000296.

60. Eller, B.S.; Yang, J.; Nemanich, R.J. Electronic surface and dielectric interface states on GaN and AlGaN. J. Vac. Sci. Technol. A 2013, 31, 050807, doi:10.1116/1.4807904.

61. Bermudez, V. The fundamental surface science of wurtzite gallium nitride. Surf. Sci. Rep. 2017, 72, 147-315, doi:10.1016/j.surfrep.2017.05.001.

62. Majchrzak, D.; Grodzicki, M.; Ciechanowicz, P.; Rousset, J.; Piskorska-Hommel, E.; Hommel, D. The Influence of Oxygen and Carbon Contaminants on the Valence Band of p-GaN(0001). Acta Phys. Pol. A 2019, 136, 585-588, doi:10.12693/aphyspola.136.585.

63. Long, J.P.; Bermudez, V.M. Band bending and photoemission-induced surface photovoltages on clean $\mathrm{n}$ and p-GaN (0001) surfaces. Phys. Rev. B 2002, 66, 121308, doi:10.1103/physrevb.66.121308.

64. M. Grodzicki, K. Moszak, D. Hommel, G.R. Bell, Band alignment and surface Fermi level pinning in GaN, Applied Surface Science. under review (n.d.).

65. S. Pugh, D. Dugdale, S. Brand, R. Abram, Electronic Structure Calculations on Nitride Semiconductors, Semiconductor Science and Technology. 14 (1999) 23. https://doi.org/10.1088/0268-1242/14/1/003.

66. Semiconductors; Springer Science and Business Media LLC, 1991;

67. Madelung, O.; Madelung, O. Semiconductors: Data Handbook. Semiconductors: Data Handbook 2004.

68. Michael E. Levinshtein, Sergey L. Rumyantsev, Michael S. Shur, Properties of Advanced Semiconductor Materials: GaN, AIN, InN, BN, SiC, SiGe I Wiley, 2001. https://www.wiley.com/enus/Properties+of+Advanced+Semiconductor+Materials $\% 3 \mathrm{~A}+\mathrm{GaN} \% 2 \mathrm{C}+\mathrm{AIN} \% 2 \mathrm{C}+\mathrm{InN} \% 2 \mathrm{C}+\mathrm{BN} \% 2 \mathrm{C}+\mathrm{SiC} \%$ 2C+SiGe-p-9780471358275 (accessed April 28, 2020).

69. Falta, J.; Schmidt, T.; Gangopadhyay, S.; Schulz, C.; Kuhr, S.; Berner, N.; Flege, J.I.; Pretorius, A.; Rosenauer, A.; Sebald, K.; et al. Cleaning and growth morphology of GaN and InGaN surfaces. Phys. Status solidi (b) 2011, 248, 1800-1809, doi:10.1002/pssb.201046574.

70. Kova, J.; Zalar, A.; Kovač, J. Surface composition changes in GaN induced by argon ion bombardment. Surf. Interface Anal. 2002, 34, 253-256, doi:10.1002/sia.1294.

71. Despiau-Pujo, E.; Chabert, P. MD simulations of GaN sputtering by Ar[sup +] ions: Ion-induced damage and near-surface modification under continuous bombardment. J. Vac. Sci. Technol. A 2010, 28, 1105, doi:10.1116/1.3460904.

72. Hunt, R.; Vanzetti, L.; Castro, T.; Chen, K.; Sorba, L.; Cohen, P.; Gladfelter, W.; Van Hove, J.; Kuznia, J.; Khan, M.; et al. Electronic structure, surface composition and long-range order in GaN. Phys. B: Condens. Matter 1993, 185, 415-421, doi:10.1016/0921-4526(93)90271-7.

73. Grodzicki, M.; Mazur, P.; Ciszewski, A. Modification of Electronic Structure of n-GaN(0001) Surface by N +-Ion Bombardment. Acta Phys. Pol. A 2017, 132, 351-353, doi:10.12693/APhysPolA.132.351. 
74. Grodzicki, M.; Mazur, P.; Ciszewski, A. Changes of electronic properties of p-GaN(0 000 1) surface after low-energy N+-ion bombardment. Appl. Surf. Sci. 2018, 440, 547-552, doi:10.1016/j.apsusc.2018.01.097.

75. Koleske, D.; Wickenden, A.E.; Henry, R.; DeSisto, W.J.; Gorman, R.J. Growth model for GaN with comparison to structural, optical, and electrical properties. J. Appl. Phys. 1998, 84, 1998-2010, doi:10.1063/1.368353.

76. Janzen, O.; Hahn, C.; Kampen, T.; Mönch, W. Explanation of multiplet spots in low-energy electron diffraction patterns of clean GaN surfaces. Eur. Phys. J. B 1999, 7, 1-4, doi:10.1007/s100510050583.

77. Tautz, F.; Sloboshanin, S.; Starke, U.; Schaefer, J. Reactivity and morphology of-faceted and (3× 3)reconstructed gan (000) epilayers grown on sapphire (0001). J. Phys. Condens. Matter 1999, 11, 8035.

78. Segev, D.; Van De Walle, C.G. Origins of Fermi-level pinning on GaN and InN polar and nonpolar surfaces. EPL (Europhysics Lett. 2006, 76, 305-311, doi:10.1209/epl/i2006-10250-2.

79. Van De Walle, C.G.; Segev, D. Microscopic origins of surface states on nitride surfaces. J. Appl. Phys. 2007, 101, 081704, doi:10.1063/1.2722731.

80. Janicki, Łukasz; Gładysiewicz, M.; Misiewicz, J.; Klosek, K.; Sobanska, M.; Kempisty, P.; Zytkiewicz, Z.R.; Kudrawiec, R. Contactless electroreflectance studies of the Fermi level position at the air/GaN interface: Bistable nature of the Ga-polar surface. Appl. Surf. Sci. 2017, 396, 1657-1666, doi:10.1016/j.apsusc.2016.12.013.

81. Shi, M.; Chinchore, A.; Wang, K.; Mandru, A.-O.; Liu, Y.; Smith, A.R. Formation of manganese $\delta$-doped atomic layer in wurtzite GaN. J. Appl. Phys. 2012, 112, 53517, doi:10.1063/1.4750034.

82. Chinchore, A.; Wang, K.; Lin, W.; Pak, J.; Smith, A.R. Atomic layer structure of manganese atoms on wurtzite gallium nitride (000 1). Appl. Phys. Lett. 2008, 93, 181908.

83. Chinchore, A.V.; Wang, K.; Shi, M.; Mandru, A.; Liu, Y.; Haider, M.; Smith, A.R.; Ferrari, V.; Barral, M.A.; Ordejon, P. Manganese $3 \times 3$ and $3 \times 3-$ R30。 structures and structural phase transition on $\mathrm{w}-\mathrm{GaN}\left(0001^{-}\right)$ studied by scanning tunneling microscopy and first-principles theory. Phys. Rev. B 2013, 87, 165426, doi:10.1103/physrevb.87.165426.

84. Waldrop, J.R.; Grant, R.W.; Wang, Y.C.; Davis, R.F. Metal Schottky barrier contacts to alpha 6H-SiC. J. Appl. Phys. 1992, 72, 4757-4760, doi:10.1063/1.352086.

85. Waldrop, J.R. Schottky barrier height of metal contacts to p-type alpha 6H-SiC. J. Appl. Phys. 1994, 75, 45484550, doi:10.1063/1.355948.

86. Reed, M.; Ritums, M.; Stadelmaier, H.; Reed, M.; Parker, C.; Bedair, S.; El-Masry, N. Room temperature magnetic $(\mathrm{Ga}, \mathrm{Mn}) \mathrm{N}$ : a new material for spin electronic devices. Mater. Lett. 2001, 51, 500-503, doi:10.1016/s0167-577x(01)00342-1.

87. Reed, M.L.; El-Masry, N.A.; Stadelmaier, H.H.; Ritums, M.K.; Reed, M.J.; Parker, C.A.; Roberts, J.C.; Bedair, S.M. Room temperature ferromagnetic properties of (Ga, Mn)N. Appl. Phys. Lett. 2001, 79, 3473-3475, doi:10.1063/1.1419231.

88. Hobbs, D.; Hafner, J.; Spišák, D. Understanding the complex metallic element Mn. I. Crystalline and noncollinear magnetic structure of $\alpha$-Mn. Phys. Rev. B 2003, 68, doi:10.1103/physrevb.68.014407.

89. Lu, Q.M.; Yue, M.; Zhang, H.G.; Wang, M.L.; Yu, F.; Huang, Q.Z.; Ryan, D.H.; Altounian, Z. Intrinsic magnetic properties of single-phase Mn1+xGa $(0<\mathrm{x}<1)$ alloys. Sci. Rep. 2015, 5, 17086, doi:10.1038/srep17086.

90. Arins, A.; Jurca, H.; Zarpellon, J.; Fabrim, Z.; Fichtner, P.F.P.; Varalda, J.; Schreiner, W.; Mosca, D. Correlation between tetragonal zinc-blende structure and magnetocrystalline anisotropy of MnGa epilayers on GaAs(111). J. Magn. Magn. Mater. 2015, 381, 83-88, doi:10.1016/j.jmmm.2014.12.068.

91. Hwang, J.I.; Ishida, Y.; Kobayashi, M.; Hirata, H.; Takubo, K.; Mizokawa, T.; Fujimori, A.; Okamoto, J.; Mamiya, K.; Saito, Y.; et al. High-energy spectroscopic study of the III-V nitride-based diluted magnetic semiconductorGa1-xMnxN. Phys. Rev. B 2005, 72, 085216, doi:10.1103/physrevb.72.085216.

92. Brudnyi, V.N. Gallium Nitride: Charge Neutrality Level and Interfaces. Russ. Phys. J. 2016, 58, 1613-1618, doi:10.1007/s11182-016-0691-1.

93. Majid, A.; Ahmad, N.; Rizwan, M.; Khan, S.U.-D.; Ali, F.A.A.; Zhu, J. Effects of Mn Ion Implantation on XPS Spectroscopy of GaN Thin Films. J. Electron. Mater. 2017, 47, 1555-1559, doi:10.1007/s11664-017-59551.

94. Kulatov, E.; Nakayama, H.; Mariette, H.; Ohta, H.; Uspenskii, Y.A. Electronic structure, magnetic ordering, and optical properties of GaN and GaAs doped with Mn. Phys. Rev. B 2002, 66, 045203, doi:10.1103/physrevb.66.045203. 
95. Barthel, S.; Kunert, G.; Gartner, M.; Stoica, M.; Mourad, D.; Kruse, C.; Figge, S.; Hommel, D.; Czycholl, G. Determination of the Fermi level position in dilute magnetic Ga1-xMnxN films. J. Appl. Phys. 2014, 115, 123706, doi:10.1063/1.4869134.

96. Titov, A.; Biquard, X.; Halley, D.; Kuroda, S.; Bellet-Amalric, E.; Mariette, H.; Cibert, J.; Merad, A.E.; Merad, G.; Kanoun, M.-B.; et al. X-ray absorption near-edge structure and valence state of Mn in (Ga,Mn)N. Phys. Rev. B 2005, 72, 115209, doi:10.1103/physrevb.72.115209.

97. Nörenberg, C.; Myhra, S.; Dobson, P.J. Scanning probe microscopy studies on the growth of palladium and nickel on GaN(0001). J. Physics: Conf. Ser. 2010, 209, 012021, doi:10.1088/1742-6596/209/1/012021.

98. Pers, J.; Grodzicki, M.; Ciszewski, A. Topography of thin films containing Ni-Ga intermetallic compounds formed on GaN(0001). Copernic. Lett. 2016, 7, 1, doi:10.12775/CL.2016.001.

99. Maruyama, T.; Hagio, Y.; Miyajima, T.; Kijima, S.; Nanishi, Y.; Akimoto, K. Effects of annealing on the interface properties between ni and p-gan. Phys. Status Solidi (A) 2001, 188, 375-378.

100. Barinov, A.; Gregoratti, L.; Kaulich, B.; Kiskinova, M.; Rizzi, A. Defect-induced lateral chemical heterogeneity at $\mathrm{Ni} / \mathrm{GaN}$ interfaces and its effect on the electronic properties of the interface. Appl. Phys. Lett. 2001, 79, 2752-2754, doi:10.1063/1.1404411.

101. Grodzicki, M.; Mazur, P.; Zuber, S.; Pers, J.; Ciszewski, A. Pd/GaN(0001) interface properties. Mater. Sci. 2014, 32, 252-256, doi:10.2478/s13536-013-0183-8.

102. Hsu, L.-S.; Williams, R.S. Electronic-structure study of the $\mathrm{Ni} \quad \mathrm{Ga}$ and the $\mathrm{Ni}$ In intermetallic compounds using X-ray photoemission spectroscopy. J. Phys. Chem. Solids 1994, 55, 305-312, doi:10.1016/00223697(94)90226-7.

103. Hsu, L.-S.; Gweon, G.-H.; Allen, J. Electronic-structure study of Ni3Al, Ni3Ga, Ni3In, and NiGa using Xray photoemission spectroscopy and Bremsstrahlung isochromat spectroscopy. J. Phys. Chem. Solids 1999, 60, 1627-1631, doi:10.1016/s0022-3697(99)00196-1.

104. Alonso, M.; Cimino, R.; Horn, K. Surface photovoltage effects in photoemission from metal-GaP(110) interfaces: Importance for band bending evaluation. Phys. Rev. Lett. 1990, 64, 1947-1950, doi:10.1103/physrevlett.64.1947.

105. Cossu, G.; Ingo, G.M.; Mattogno, G.; Padeletti, G.; Proietti, G. XPS investigation on vacuum thermal desorption of UV/ozone treated GaAs(100) surfaces. Appl. Surf. Sci. 1992, 56, 81-88, doi:10.1016/01694332(92)90219-n.

106. Kraut, E.A.; Grant, R.W.; Waldrop, J.R.; Kowalczyk, S.P. Precise Determination of the Valence-Band Edge in X-Ray Photoemission Spectra: Application to Measurement of Semiconductor Interface Potentials. Phys. Rev. Lett. 1980, 44, 1620-1623, doi:10.1103/PhysRevLett.44.1620.

107. Arabasz, S.; Bergignat, E.; Hollinger, G.; Szuber, J. XPS analysis of surface chemistry of near surface region of epiready GaAs(100) surface treated with (NH4)2Sx solution. Appl. Surf. Sci. 2006, 252, 7659-7663, doi:10.1016/j.apsusc.2006.03.061.

108. Grodzicki, M.; Mazur, P.; Wasielewski, R.; Ciszewski, A. Physicochemical properties of the Sb/p-SiC interface. Vac. 2017, 146, 216-220, doi:10.1016/j.vacuum.2017.09.037.

109. Wang, M.W. Study of interface asymmetry in InAs-GaSb heterojunctions. J. Vac. Sci. Technol. B: Microelectron. Nanometer Struct. 1995, 13, 1689, doi:10.1116/1.587879.

(C) 2020 by the authors. Submitted for possible open access publication under the terms and conditions of the Creative Commons Attribution (CC BY) license (http://creativecommons.org/licenses/by/4.0/). 